\title{
Dynamin 1- and 3-Mediated Endocytosis Is Essential for the Development of a Large Central Synapse In Vivo
}

\author{
Fan Fan, ㄴaura Funk, and $\odot$ Xuelin Lou \\ Department of Neuroscience, School of Medicine and Public Health, University of Wisconsin-Madison, Madison, Wisconsin 53706
}

\begin{abstract}
Dynamin is a large GTPase crucial for endocytosis and sustained neurotransmission, but its role in synapse development in the mammalian brain has received little attention. We addressed this question using the calyx of Held $(\mathrm{CH})$, a large nerve terminal in the auditory brainstem in mice. Tissue-specific ablation of different dynamin isoforms bypasses the early lethality of conventional knock-outs and allows us to examine $\mathrm{CH}$ development in a native brain circuit. Individual gene deletion of dynamin 1, a primary dynamin isoform in neurons, as well as dynamin 2 and 3, did not affect $\mathrm{CH}$ development. However, combined tissue-specific knock-out of both dynamin 1 and 3 (cDKO) severely impaired $\mathrm{CH}$ formation and growth during the first postnatal week, and the phenotypes were exacerbated by further additive conditional knock-out of dynamin 2. The developmental defect of $\mathrm{CH}$ in cDKO first became evident on postnatal day 3 (P3), a time point when $\mathrm{CH}$ forms and grows abruptly. This is followed by a progressive loss of postsynaptic neurons and increased glial infiltration late in development. However, early CH synaptogenesis before protocalyx formation was not altered in cDKO. Functional maturation of synaptic transmission in the medial nucleus of the trapezoid body in CDKO was impeded during development and accompanied by an increase in the membrane excitability of medial nucleus of the trapezoid body neurons. This study provides compelling genetic evidence that $\mathrm{CH}$ formation requires dynamin 1- and 3-mediated endocytosis in vivo, indicating a critical role of dynamin in synaptic development, maturation, and subsequent maintenance in the mammalian brain.
\end{abstract}

Key words: circuit assembly; dynamin; neural activity; neurodegeneration; synaptic development; synaptogenesis

Significance Statement

Synaptic development has been increasingly implicated in numerous brain disorders. Dynamin plays a crucial role in clathrinmediated endocytosis and synaptic transmission at nerve terminals, but its potential role in synaptic development in the native brain circuitry is unclear. Using the calyx of Held, a giant nerve terminal in the mouse brainstem, we evaluated the role of dynamin in this process by using tissue-specific knock-out (KO) of three different dynamin isoforms (dynamin 1,2, and 3 ) individually and in combination. Our data demonstrated that dynamin is required for the formation, functional maturation, and subsequent survival of the calyx of Held. This study highlights the important role of dynamin-mediated endocytosis in the development of central synapses in the mammalian brain.

\section{Introduction}

Synapse shape and size vary greatly, ranging from small synaptic boutons containing a single active zone (AZ) with a few vesicles to large nerve terminals harboring multiple AZs and thousands of

Received Oct. 17, 2015; revised April 19, 2016; accepted April 25, 2016.

Author contributions: F.F. and X.L. designed research; F.F., L.F., and X.L. performed research; F.F., L.F., and X.L. analyzed data; F.F. and X.L. wrote the paper.

This work is supported in part by National Institutes of Health Grants R01DK093953 and P30NS069271 and Brain Research Foundation Grant BRFSG201407. We thank Pietro De Camilli and Shawn Ferguson for providing the conditional mice carrying the floxed Dnm1, 2, and 3; Patrick Charnay and Ralf Schneggenburger for Krox20Cre mice; Juliana Maedke, Chen Ji, and Justin Chia-Ni Kao for technical support; and Meyer Jackson and Bill Chiu for reading the manuscript and suggestions.

The authors declare no competing financial interests.

Correspondence should be addressed to Dr. Xuelin Lou, Department of Neuroscience, University of WisconsinMadison, Madison, WI 53706. E-mail: xlou3@wisc.edu.

DOI:10.1523/JNEUROSCI.3804-15.2016

Copyright $\odot 2016$ the authors $\quad 0270-6474 / 16 / 366097-19 \$ 15.00 / 0$ vesicles (Walmsley et al., 1998; Atwood and Karunanithi, 2002). Synaptic structures are tightly regulated to support characteristic neurotransmission with reliability, speed, and plasticity (Borst and Soria van Hoeve, 2012; Petrof and Sherman, 2013). Abnormal synaptic development has been implicated in numerous brain diseases, such as epilepsy, autism, schizophrenia, and intellectual disability (Melom and Littleton, 2011). However, the mechanism underlying the regulation of synaptic morphology in the mammalian brain remains poorly understood.

Synaptic endocytosis is essential to support normal synaptic transmission at nerve terminals (Saheki and De Camilli, 2012), and it has also been frequently implicated to regulate peripheral synapse development (Koh et al., 2004; Marie et al., 2004; Dickman et al., 2006). For example, both cytoplasmic FMRP (fragile X mental retardation protein) interacting protein (CYFIP) and nervous wreck regulate the growth of neuromuscular junctions 
(NMJs) through endocytic regulation of bone morphogenetic protein (BMP) signaling and actin cytoskeleton ( $\mathrm{O}^{\prime} \mathrm{Connor}-\mathrm{Giles}$ et al., 2008; Zhao et al., 2013). Accordingly, perturbations of genes associated with endocytosis, such as dynamin, AP180, endophilin, synaptojanin, and Dap160/intersectin, lead to numerous smaller satellite boutons and aberrant AZ spacing at Drosophila NMJs (Koh et al., 2004; Marie et al., 2004; Dickman et al., 2006). Both synaptic activity (Andreae and Burrone, 2014) and intracellular signaling pathways (Bayat et al., 2011) have been proposed to contribute to this phenotype. In mammals, genetic studies have established crucial functions of different endocytic genes in synaptic vesicle recycling, such as dynamin (Ferguson et al., 2007; Boumil et al., 2010), AP-2 (Kononenko et al., 2014), endophilin (Milosevic et al., 2011), and synaptojanin (Cremona et al., 1999). However, the in vivo impact of endocytosis on CNS synapse development has not been evaluated, due partly to perinatal lethality of conventional knock-out (KO) mice and huge diversity of different synaptic connections in the brain.

The calyx of Held $(\mathrm{CH})$ is a large CNS synapse originating from globular bushy cell (GBC) in the ventral cochlear nucleus (VCN) and innervating the principal neuron in the contralateral medial nucleus of the trapezoid body (MNTB) (Schneggenburger and Forsythe, 2006; Borst and Soria van Hoeve, 2012). The $\mathrm{CH}$ is one of the best-characterized models for CNS synapses (von Gersdorff and Borst, 2002; Neher and Sakaba, 2008; Kochubey et al., 2011; Wu et al., 2014a). It has a giant, calyxshaped terminal that is easily identifiable and accessible to electrophysiologists. Each $\mathrm{CH}$ contains 500-800 AZs with up to 70,000-320,000 vesicles (Sätzler et al., 2002; Schneggenburger and Forsythe, 2006; Qiu et al., 2015). The $\mathrm{CH}$ develops in three characteristic stages: (1) the initial synapse assembly through small, dendritic contacts between GBC axon terminals and MNTB neurons by P2; (2) rapid protocalyx formation and growth (P2 and P5), which covers over half of the postsynaptic neuron surface within 2 weeks (Hoffpauir et al., 2006; Soria Van Hoeve and Borst, 2010; Holcomb et al., 2013; Xiao et al., 2013); and (3) continuous structural optimization during maturation, including $\mathrm{CH}$ compartmentalization, more isolated AZs (Taschenberger et al., 2002), and tighter vesicle- $\mathrm{Ca}^{2+}$ channel coupling (Fedchyshyn and Wang, 2005; Yang et al., 2010). In parallel with the dramatic structural remodeling, particularly in the second phase, neurotransmission undergoes rapid increase (Hoffpauir et al., 2006; Rodríguez-Contreras et al., 2008; Hoffpauir et al., 2010), and the subsequent structural refinement further ensures timing precision and transmission fidelity (Taschenberger and von Gersdorff, 2000; Taschenberger et al., 2002; Koike-Tani et al., 2005; Takahashi, 2005).

The $\mathrm{CH}$ is endowed with a few unique properties, such as large size, primarily one-to-one innervation, and fast morphological development. Thus, it is an ideal model to study CNS synapse development. To examine the role of dynamin-mediated endocytosis at this synapse, we generated tissue-specific KOs of dynamin 1,2, and 3, both individually and in combination. Both morphological and functional data revealed an essential role for dynamin-mediated endocytosis in CNS synapse development in the mammalian brain.

\section{Materials and Methods}

Generation of individual and combinatorial tissue-specific KO of dynamin 1,2 , and 3 in mice. Multiple lines of dynamin conditional $\mathrm{KO}(\mathrm{cKO})$ were generated by crossing the mouse strains carrying floxed Dnm1, Dnm2, and Dnm3 (Ferguson et al., 2009; Raimondi et al., 2011) and the Krox20Cre knock-in mice (Voiculescu et al., 2000). The Krox20Cre strain carries a Cre-encoding sequence at the locus of Krox20 (also called $E G R 2$ ), a zinc-finger transcriptional factor gene expressed primarily in the auditory brainstem, and it has been successfully applied to the $\mathrm{CH}$ study (Han et al., 2011; Michalski et al., 2013; Xiao et al., 2013). For dynamin $1 \mathrm{cKO}$ mice, the $\mathrm{Dnm}^{\mathrm{f} / \mathrm{+}} \mathrm{Krox} 2 \mathrm{O}^{+/ \mathrm{Cre}}$ mice (F1) from the first generation were further crossed with $D n m 1^{f / f}$ to give rise to $D n m 1^{f /}$ ${ }^{\Delta}$ Krox $20^{+/ C r e}$ and $\operatorname{Dnm}^{f / \Delta}$ (F2) due to Krox20Cre-driven germline recombination (Voiculescu et al., 2000). Dnm $1^{f / \Delta}$ Krox $20^{+/ C r e}$ mice were further crossed with $D n m 1^{f / f}$ to generate dynamin $1 \mathrm{cKO}\left(D n m 1^{f /}\right.$ ${ }^{\Delta}$ Krox $20^{+/ C r e}$ ) (Mahapatra et al., 2016), in which dynamin 1 was deleted in Krox20Cre-positive cells in the brainstem starting from around embryo day 9 (E9, expression onset of Krox20Cre) onward (Voiculescu et al., 2000). Littermates carrying no Krox20Cre were used as controls. Dynamin 2 cKO was similarly generated as in Dynamin 1 cKO. Dynamin 3 KO mice (Raimondi et al., 2011) were overall healthy as the wild-type. For combinatorial dynamin cKOs, Krox20Cre mice were crossed with conditional triple dynamin mice $\left(D n m 1^{f / f}, 2^{f / f}, 3^{f / f}\right)$ in which all three dynamin genes were flanked by LoxP sites (Park et al., 2013); this generated mice carrying different combinations of dynamin deletions. In this study, conditional dynamin 1 and 3 double $\mathrm{KO}\left(\operatorname{Dnm} 1^{f / \Delta}, 3^{f / \Delta}, \mathrm{Krox} 20^{+/ C r e}\right)$ is referred to as "cDKO." The littermates without Krox $20^{\mathrm{Cre}}$ showed no evident phenotypes and were used as controls. At an early stage of this project, we also crossed Krox20Cre with Dnm1 $1^{f / f}, 3^{-1-}$ to generate the double deletion of dynamin 1 and 3 in $\mathrm{CH}\left(\mathrm{Dnmi}^{f / \Delta}, 3^{-/-}\right.$, Krox $20^{+/ C r e}$, dynamin $1 \mathrm{cKO}$ in combination with dynamin 3 conventional $\mathrm{KO}$ ). These mice phenocopied cDKO regarding the $\mathrm{CH}$ development; thus, data from these mice were pooled with the cDKO. Dynamin triple $\mathrm{cKO}$ mice died within a few hours after birth, preventing their use in the $\mathrm{CH}$ postnatal development study here. Thus, we focused on the cDKO mice (with either sex) for experiments.

To examine the Krox20Cre expression pattern in brainstems, we used the dual-color reporter mice Rosa ${ }^{m T / m G}$ mice (Muzumdar et al., 2007) (The

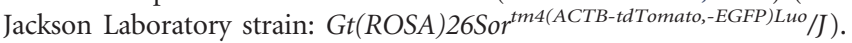
These mice carried a floxed cassette containing plasma membrane-targeted tandem dimer Tomato $(m T)$ and EGFP $(m G)$ gene after a chimerical CMV $\beta$-actin promoter in the ROSA 26 locus. After crossing them with the Krox20Cre strain, removing of $m T$ allowed $m G$ to express in Cre-positive cells, generating a color change (from red to green) in the cell plasma membrane. The hearing was simply evaluated using a clicker in a quiet environment, without any vision interruption to the mice. The sound-stimulated responses in normal mice (e.g., ear movement induced by sound) disappeared in $\mathrm{cDKO}$ mice. Animal care and protocol were approved by the Institutional Animal Care and Use Committee of the University of Wisconsin-Madison and were in accordance with the National Institutes of Health Guide for the care and use of laboratory animals.

Immunofluorescence staining and confocal imaging. Mouse brains with different genotypes were dissected at different postnatal developmental stages (P0-P20). The brain tissues were fixed overnight with $4 \%$ PFA + $4 \%$ sucrose in $0.12 \mathrm{M}$ sodium phosphate buffer unless otherwise specified. Brain regions containing MNTB were cut into a series of thin $(30-50 \mu \mathrm{m})$ sections with a VT1200 microtome (Leica) and placed on glass slides. For active zones and postsynaptic density (PSD) staining, brain tissues were fixed in $4 \%$ PFA for $4-6 \mathrm{~h}$, and $6-10 \mu \mathrm{m}$ freezing sections were prepared. Immunohistochemistry was performed as described previously (Fan et al., 2015) with minor modifications. Tissue sections were incubated with blocking buffer $(0.4 \%$ Triton X-100 + 3\% $\mathrm{BSA}+2 \%$ goat serum) for $1 \mathrm{~h}$ and incubated with the primary antibodies for $2 \mathrm{~h}$. After thorough washing, tissue sections were incubated with the different secondary antibodies conjugated with fluorescent dye for $50 \mathrm{~min}$, then washed thoroughly and sealed by a coverslip with Fluoromount-G (Southern Biotechnology, 0100-01).

Antibodies used in this study are as follows: dynamin 1 (Epitomics, 1851-1, rabbit, 1:200), dynamin 3 (from Pietro DeCamilli laboratory, mouse, 1:100), vesicular glutamate transporter-1 (vGlut1) (Millipore, Ab5905, guinea pig, 1:800), parvalbumin (PV-25, Swant, rabbit, 1:500), Bassoon (Abcam, mouse, 1:200), PSD-95 (Invitrogen, rabbit, 1:200; or NeuroMab, mouse, 1:100), GFAP (NeuroMab, mouse, clone N206A/8, 1:200), Ibal (Wako-chem, rabbit, 1:500). The secondary antibodies were conjugated with different Alexa fluorophores (Invitrogen, 1:300). The 
specificity of antibodies for dynamin 1 and 3 has been tested by Western blots by using different dynamin KO (Ferguson et al., 2007; Raimondi et al., 2011; Fan et al., 2015). In the DiI tracing experiments, small DiI crystals were applied carefully to the single side of VCN after a small lesion in fixed brains and left at $4^{\circ} \mathrm{C}$ for $\sim 2$ months. Coronal sections were prepared as described previously (Mahapatra et al., 2016) and imaged shortly after tissue sections were made.

Confocal images were taken under a spinning disk confocal (SDC) microscope equipped with multiple objectives $(20 \times, 60 \times$, and APO $100 \times$ oil with NA 1.49) (Fan et al., 2015). Only a few images were collected using epifluorescence microscopy. Samples were excited with appropriate lasers $(405,488,561$, and $642 \mathrm{~nm})$; emitted light was filtered through matching bandpass filters according to fluorophores used; images were collected by an EMCCD camera (Andor, iXon X3, DU897, back illumination). Images for direct comparisons were acquired and displayed with the same settings (e.g., laser intensity, exposure time, EM gain, displaying contrast levels) unless otherwise specified.

Morphological analysis was performed using NIS-Elements AR imaging software (Nikon, version 4.12). The sizes of MNTB areas and neurons were first examined visually for vGlutl fluorescence. MNTBs were distinguishable from other regions, and their areas were defined using the freehand drawing tool. Neuron sizes were detected and binary-masked with the same fluorescence intensity threshold for both control and $\mathrm{KO}$ images. Three-dimensional images of $\mathrm{CH}$ were reconstructed using serial optical $Z$-sections with an increment of 200-500 nm under high magnification $(100 \times)$ and rendered in NIS-Element AR, with a rendering threshold adjusted to better visualize the fine structures of samples. The size and density of nerve terminals in MNTBs were detected based on vGlut1 fluorescence under high magnification $(100 \times)$, in combination with the intensity threshold function in NIS-Elements AR (see Fig. $5 C$ ). The presynaptic areas may be overestimated due to the presence of some small terminals whose size was below the diffraction limit of light microscopy; however, this should not affect our conclusion because the exact same analysis was applied to both control and KO groups. In most experiments, a minimum of 3 mice were used for each dataset. Brain slices that cut through the middle anterior-posterior levels of MNTB were used for imaging analysis.

Brain slices and patch-clamp recording. Brain slices $(200 \mu \mathrm{m})$ containing MNTBs were prepared from mice at specified ages, and patch-clamp recordings were performed as previously described (Lou et al., 2008a). Patch pipettes had resistances of $2-4 \mathrm{M} \Omega$. The series resistance $\left(R_{s}\right)$ was compensated up to $95 \%$; recordings with $R_{\mathrm{s}}>15 \mathrm{M} \Omega$ were excluded from analysis. No offline $R_{s}$ correction was applied. Neuron membrane potential $\left(V_{\mathrm{h}}\right)$ was held at $-80 \mathrm{mV}$ unless otherwise specified, and data were acquired at $20 \mathrm{kHz}$. The extracellular solution contained the following (in mM): $120 \mathrm{NaCl}, 2.5 \mathrm{KCl}, 25 \mathrm{NaHCO}_{3}, 1.25 \mathrm{NaH}_{2} \mathrm{PO}_{4}, 2 \mathrm{CaCl}_{2}, 1$ $\mathrm{MgCl}_{2}, 25$ glucose, 3 myoinositol, $2 \mathrm{Na}$-pyruvate, $0.4 \mathrm{~L}$-ascorbic acid, $\mathrm{pH}$ 7.4, with $95 \% \mathrm{O}_{2}$ and $5 \% \mathrm{CO}_{2}$ bubbling. Strychnine- $\mathrm{HCl}(2 \mu \mathrm{M})$, bicuculline $(10 \mu \mathrm{M})$, and D-AP5 $(50 \mu \mathrm{M})$ were prepared freshly and included in extracellular solution during spontaneous EPSC recordings. The patch pipette solution (IS) for spontaneous EPSC (sEPSC) recordings contained the following (in mM): 137 Cs-gluconate, 10 HEPES, 20 TEA-Cl, 5 $\mathrm{Na}_{2}$-phosphocreatinine, $4 \mathrm{Mg}$-ATP, $0.3 \mathrm{Na}_{2} \mathrm{GTP}, 5$ Cs-EGTA, pH 7.2. The IS for current-clamp recordings contained the following (in $\mathrm{mM}$ ): $137 \mathrm{~K}$-gluconate, $10 \mathrm{HEPES}, 5 \mathrm{Na}_{2}$-phosphocreatinine, $4 \mathrm{MgATP}, 0.3$ $\mathrm{Na}_{2}$ GTP, 0.1 K-EGTA, pH 7.2. Holding current was set to zero when measuring the resting membrane potentials. D-AP5 was from Tocris Bioscience, and the other chemicals were from Sigma.

Electrophysiological data were analyzed in IgorPro (WaveMetrics). sEPSC events were detected with a template-matching algorithm (Clements and Bekkers, 1997) implemented in IgorPro (kindly provided by Volker Scheuss and Holger Taschenberger). The average values of synaptic transmission were derived from the mean parameters of each neuron. We fitted sEPSC traces with a double-exponential function to obtain time constants of fast $\left(\tau_{\text {fast }}\right)$ and slow $\left(\tau_{\text {slow }}\right)$ decays and their relative amplitudes $\left(\mathrm{A}_{\text {fast }}\right.$ and $\left.\mathrm{A}_{\text {slow }}\right)$, respectively. The weighted decay time constant follows the equation $\tau_{\text {mean }}=\mathrm{A}_{\text {fast }} \times \tau_{\text {fast }}+\mathrm{A}_{\text {slow }} \times \tau_{\text {slow }}$. The absolute parameter values of sEPSCs at each age and genotype are presented in Table 1; their relative changes (in percentage) at P8-P10 were compared with the average value at $\mathrm{P} 4$ in each genotype, as shown in Figure $8 K$.

Data analysis and statistics. Values are presented as mean \pm SEM unless otherwise indicated. Statistical analyses were performed using unpaired two-tailed Student's $t$ test; the significance level was set at $p<0.05$.

\section{Results \\ Developmental changes in dynamin 1 and 3 expression levels in MNTBs}

Three dynamin genes (Dnm1, Dnm2, and Dnm3) are expressed in mammals with different expression levels, with dynamin 1 being the most abundant isoform in the brain (Ferguson and De Camilli, 2012). Dynamin mRNA levels are upregulated with neural development in mammals (Nakata et al., 1991). We explored the developmental regulation of dynamin 1 and 3 in MNTBs in mice. Immunohistochemistry showed a significant increase of dynamin 1 expression levels within the first 2 postnatal weeks (Fig. $1 A, B)$. Dynamin 1 was expressed both presynaptically and postsynaptically in P10 and P20 (Fig. $1 B$, yellow; see the intensity profile of dynamin 1 fluorescence across the presynaptic region from a $\mathrm{P} 10 \mathrm{CH}$, Fig. $1 B$, right). However, at $\mathrm{P} 1$, its fluorescence was very weak in the MNTBs. We next examined dynamin 1 expression with an increased exposure time in P1 MNTBs and two different negative controls at the same imaging setting: cDKO MNTB and MNTBs without anti-dynamin antibody (Fig. $1 C)$. Some small fluorescent puncta were partially colocalized with vGlut1 at P1. Many, but not all, of these fluorescent puncta disappeared in $\mathrm{CDKO}$ MNTB (Fig. 1C); the remaining puncta in cDKO likely reflect nonspecific staining. Images omitting antidynamin 1 antibody showed only even background fluorescence. These data suggest that dynamin-1 levels are very low in P1 MNTB regions. Similarly, dynamin 3 expression was also visible in MNTBs and slightly increased during development (Fig. $1 D, E)$. Dynamin 3 fluorescence appeared in both presynaptic and postsynaptic regions at P10, with a slightly higher intensity in postsynaptic neurons in many cells (Fig. 1E, right). Figure $1 F$ shows the direct comparisons of dynamin 3 staining with two negative controls under the same conditions. Together, the expression level of dynamin 1, as well as dynamin 3, is very low at an early developmental stage in MNTBs (P1) but is strongly upregulated in parallel with synaptic activity and neuron development (P10 afterward).

\section{Tissue-specific deletions of different dynamin isoforms individually do not affect $\mathrm{CH}$ development}

We next generated tissue-specific dynamin $\mathrm{KO}$ in auditory brainstem using krox20Cre knock-in mice (Voiculescu et al., 2000) and different combinations of dynamin isoforms. This was necessary because of the perinatal lethality of the conventional dynamin KOs (Ferguson et al., 2009; Raimondi et al., 2011; Lou et al., 2012). We first confirmed the Krox20Cre expression pattern in the juvenile mouse brain using a dual-color reporter mouse line (see Materials and Method). Consistent with the previous work (Voiculescu et al., 2000; Han et al., 2011), we observed a strong expression of EGFP primarily in the rhombomere 3 and 5 (Fig. 2A) in the juvenile mouse brain. GFP fluorescence was very strong in GBCs in VCN (data not shown) and MNTBs (Fig. $2 A, B$ ), but not in other large regions of the brainstem and cerebellum.

To test the role of dynamin in $\mathrm{CH}$ development, we tissuespecifically knocked out Dnm1,2, and 3 genes in mice individually and in combination. Toward this end, Krox20Cre mice were crossed with the mice harboring floxed Dnm1, Dnm2 
A

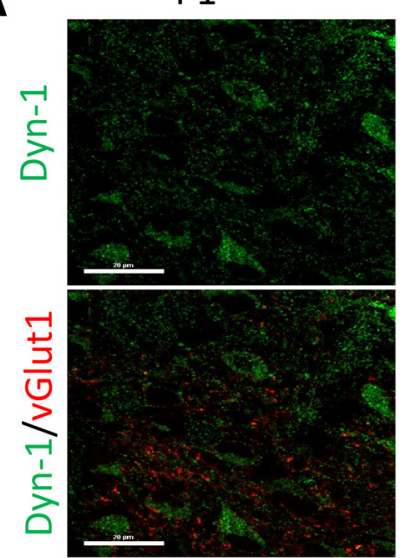

P5
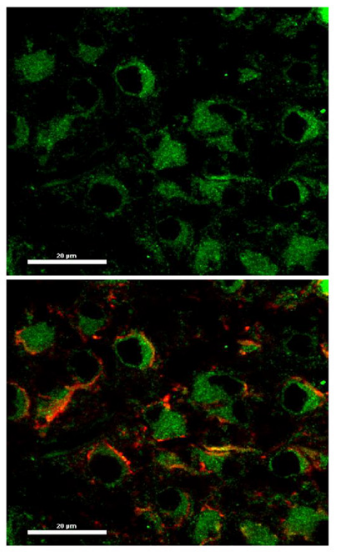

B
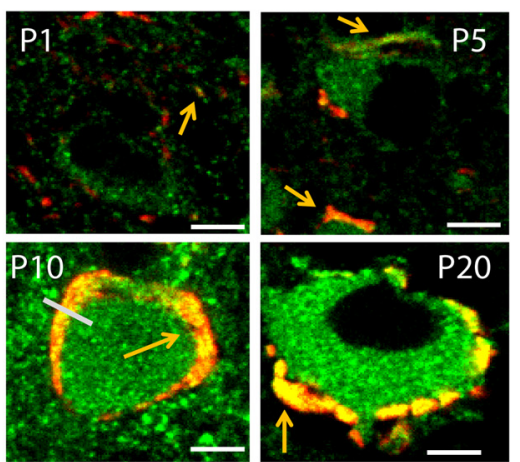

D

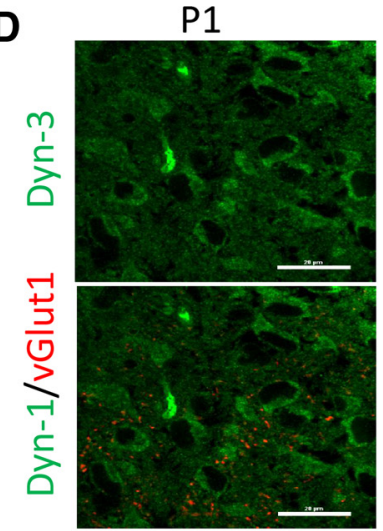

E
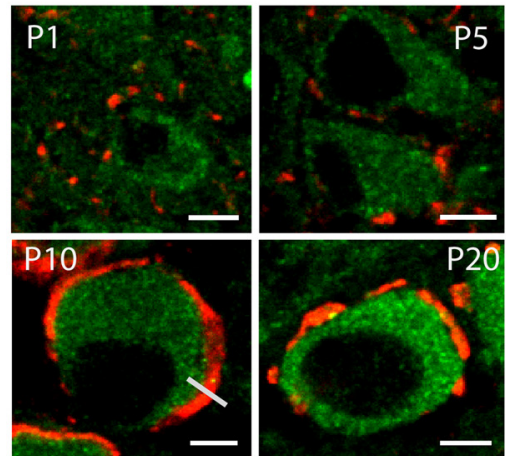

P5
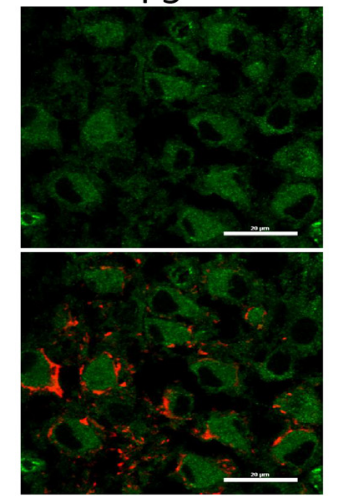

P5

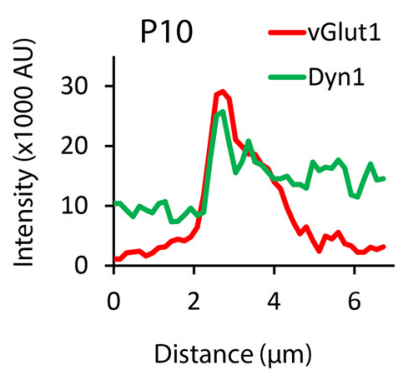

P10
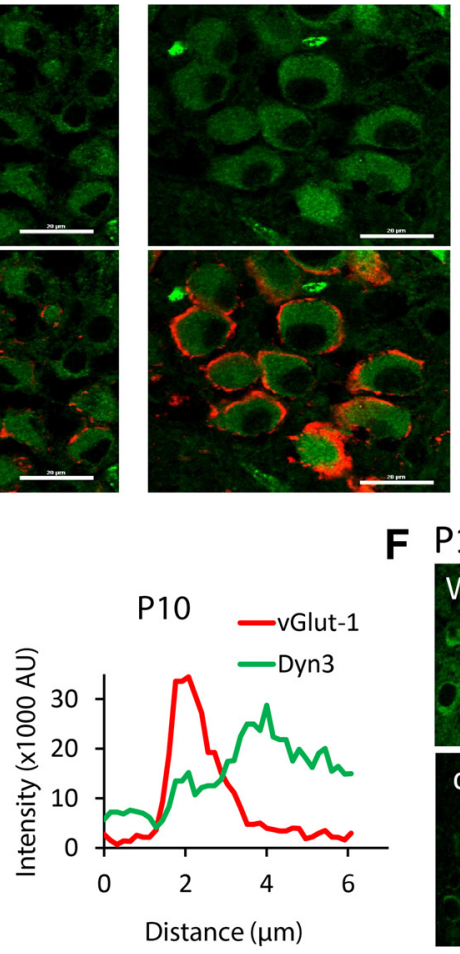

P10
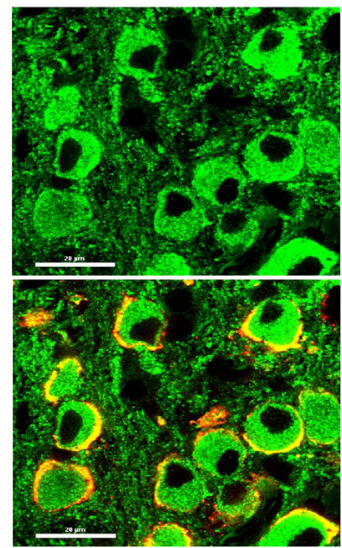

C P1 (longer exposure)

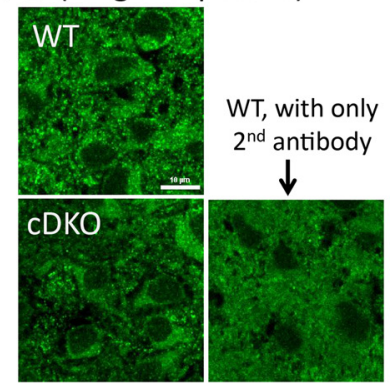

P20

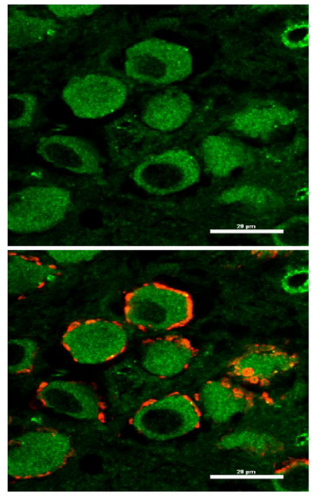

F P1 (longer exposure)

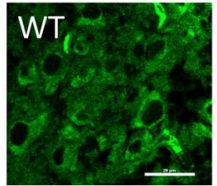

WT, with only $2^{\text {nd }}$ antibody

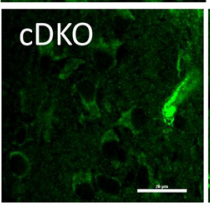

P20

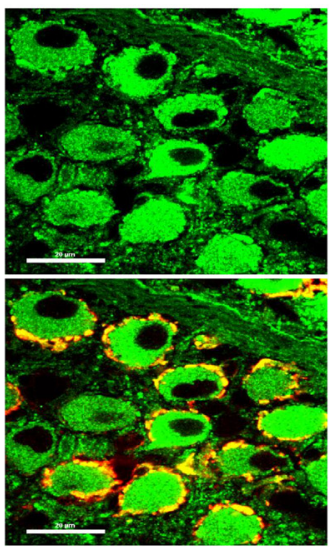
ntibody

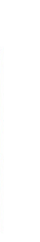

\section{.}


A

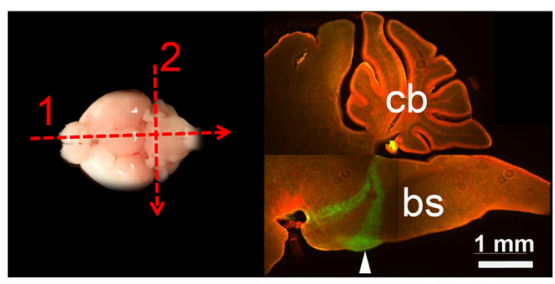

C

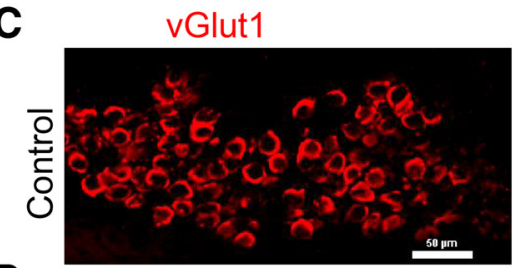

D

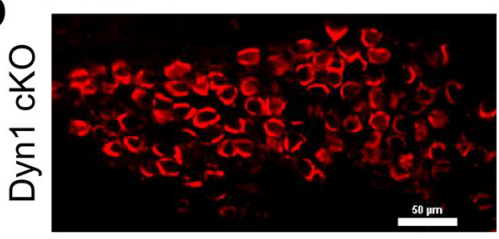

B

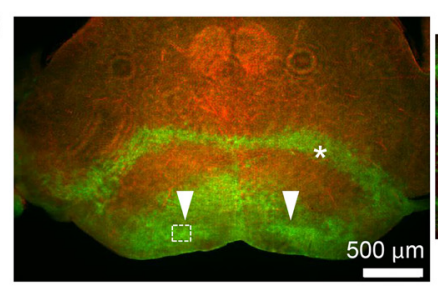

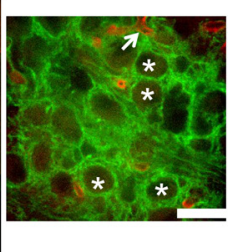

Merge
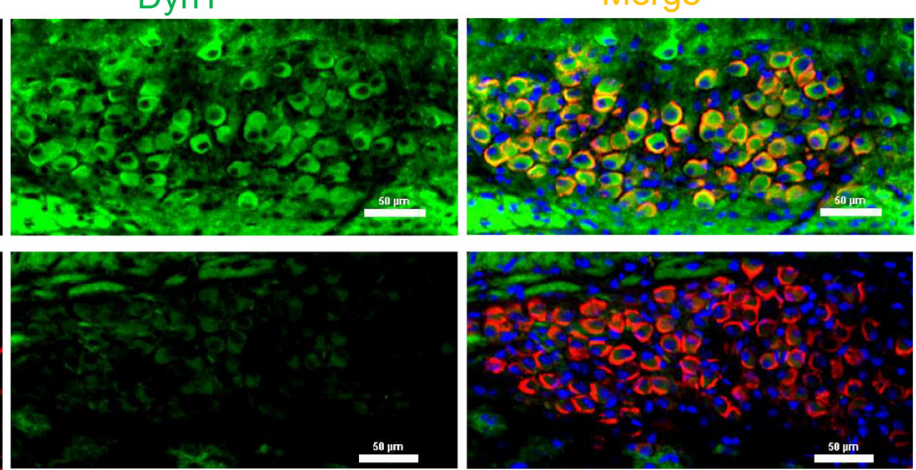

E

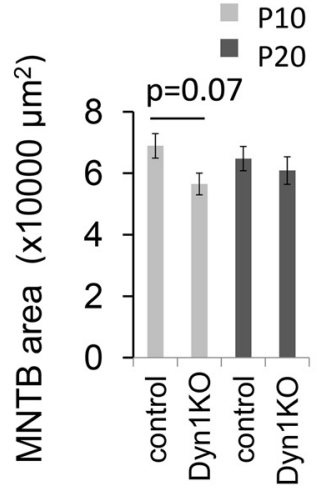

F P20

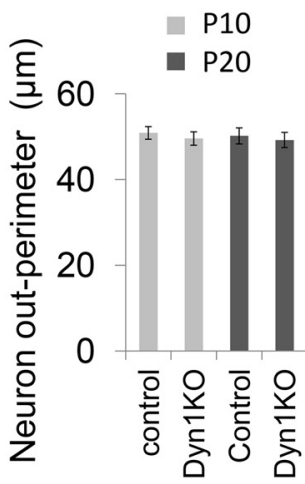

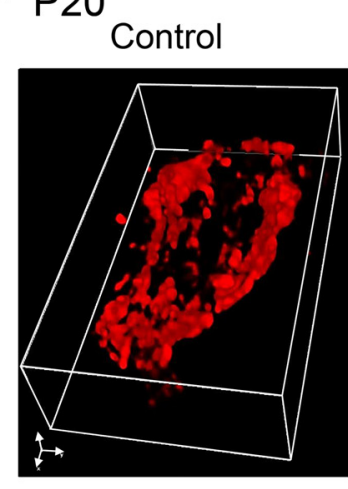

\section{Dyn1 cKO}

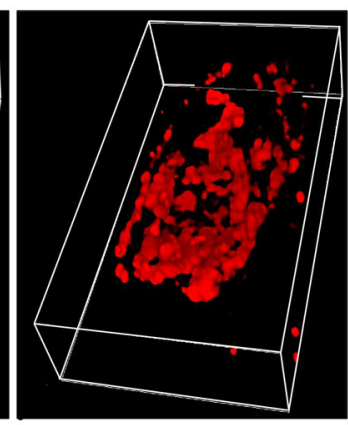

Figure 2. Conditional dynamin $1 \mathrm{KO}$ does not affect $\mathrm{CH}$ development in mice. $\boldsymbol{A}, \boldsymbol{B}$, Tissue-specific Krox20-Cre expression in young mouse brains revealed by the dual-color reporter mice. EGFP fluorescence showed high levels of Krox20 Cre expression in a sagittal ( $\boldsymbol{A}$, right) and a coronal $(\boldsymbol{B})$ brain section cut through an MNTB from a Rosa ${ }^{m T / m G} \mathrm{Krox20} C \mathrm{re} \mathrm{mouse} \mathrm{at} \mathrm{P10.} \mathrm{Arrowheads} \mathrm{indicate}$ MNTB regions. Cb, Cerebellum; bs, brainstem. $\boldsymbol{B}$, Inset, An enlarged view of the MNTB demonstrated strong EGFP expression in $C$ H and MNTB neurons $\left({ }^{*}\right)$ but not blood vessels (arrow). $\boldsymbol{C}$, $\boldsymbol{D}$, Efficient dynamin 1 depletion at the $\mathrm{CH}$ in Dyn $1 \mathrm{CKO}$ mice at P10. Images were acquired and displayed at the same imaging setting. $\boldsymbol{E}$, MNTB size ( $n=6$ or 7 slices from 3 mice in each genotype and age) and individual neuron size ( $n=98-125$ neurons at each age) at P8 -P10 and P20 from control and dynamin 1 cKO mice. $F$, Representative 3D structure of $C H$ at $P 20$. Serial optical sections of vGlut 1 fluorescence were acquired with a $0.3 \mu \mathrm{m} z$-increment and restructured using $\alpha$ blending. Scale bars: $\boldsymbol{A}, 1 \mathrm{~mm} ; \boldsymbol{B}, 500 \mu \mathrm{m} ; \boldsymbol{B}$, inset, $20 \mu \mathrm{m} ; \boldsymbol{C}, \boldsymbol{D}, 50 \mu \mathrm{m} ; \boldsymbol{D}, \boldsymbol{x}$-axis and $y$-axis, $0.16 \mu \mathrm{m} ; \boldsymbol{D}, \boldsymbol{Z}$-axis, $0.2 \mu \mathrm{m}$.

(Ferguson et al., 2009), or Dnm3 (Raimondi et al., 2011), respectively. Dynamin $1 \mathrm{cKO}$ mice were viable and outwardly normal, in contrast to the short lifespan and smaller size of conventional dynamin $1 \mathrm{KO}$ mice (Ferguson et al., 2007; Lou et al., 2008b). Immunostaining revealed efficient dynamin 1 depletion in MNTBs (Fig. 2C,D); the weak signal left in dynamin $1 \mathrm{cKO}$ presumably reflected nonspecific background fluorescence. The $\mathrm{CH}$ was normal at P8-P10 in the absence of dynamin 1, the most abundant isoform in the brain ( $>90 \%$ of total dynamin levels) (Ferguson et al., 2007). Quantitative analysis with threshold masking demonstrated similar MNTB area and individual neuron size between control and dynamin $1 \mathrm{cKO}$ at P8-P10 and P20 (Fig. 2E). Figure $2 F$ showed a representative $3 \mathrm{D}$ CH structure at P20 visualized by vGlut 1 fluorescence, and no obvious morphological differences were observed between control and dynamin $1 \mathrm{cKO}$. Futher functional analysis revealed an interesting role of dynamin-1 in short-term synaptic depression during high-frequency neurotransmission at the mature $\mathrm{CH}$ (Mahapatra et al., 2016).
As the major non-neuronal isoform, dynamin 2 is ubiquitously distributed in different types of cells (Cao et al., 1998); the embryonic lethality of conventional dynamin $2 \mathrm{KO}$ mice (Ferguson et al., 2009) suggests its essential role in early embryonic development. Interestingly, the dynamin $2 \mathrm{cKO}$ mice appeared outwardly normal, presumably due to the late onset of Krox20Cre activity during embryo development $(\sim \mathrm{E} 9)$ or its selective expression only in $\mathrm{r} 3$ and $\mathrm{r} 5$ of the brain. The $\mathrm{CH}$ had normal morphology in dynamin $2 \mathrm{cKO}$ (data not shown). A similar phenotype was also observed in dynamin 3 conventional KO (Raimondi et al., 2011). Compared with the severe developmental defect of NMJs in Drosophila (Dickman et al., 2006), the normal CH structure observed in individual dynamin $\mathrm{KO}$ mice likely indicates the functional redundancy among dynamin isoforms in these neurons to support its normal development. Consistent with this idea, previous studies demonstrated that dynamin 1 and 3 double $\mathrm{KO}$ worsens the phenotype of dynamin 1 or $3 \mathrm{KO}$ alone (Raimondi et al., 2011; Lou et al., 2012). 
A
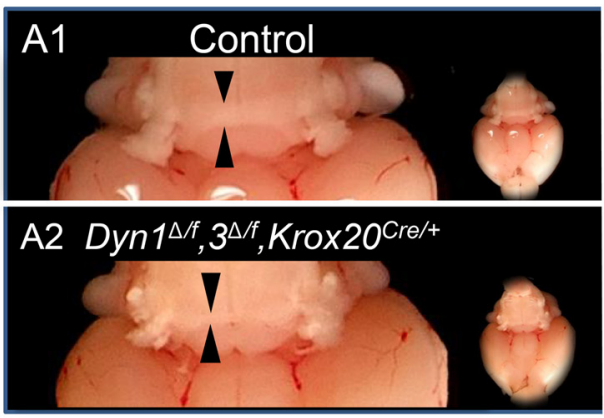

B

Control
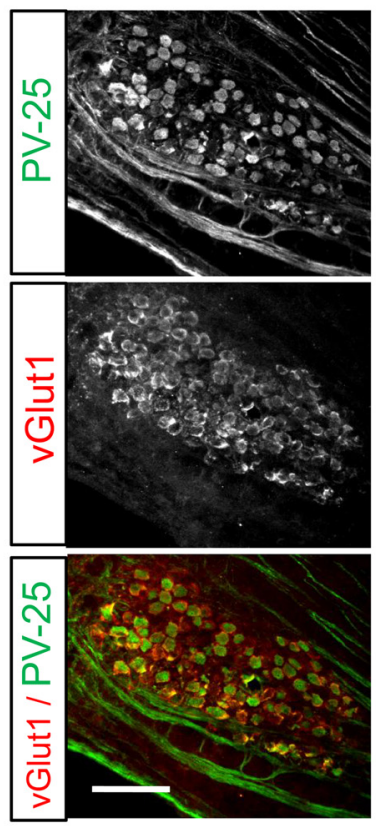

E
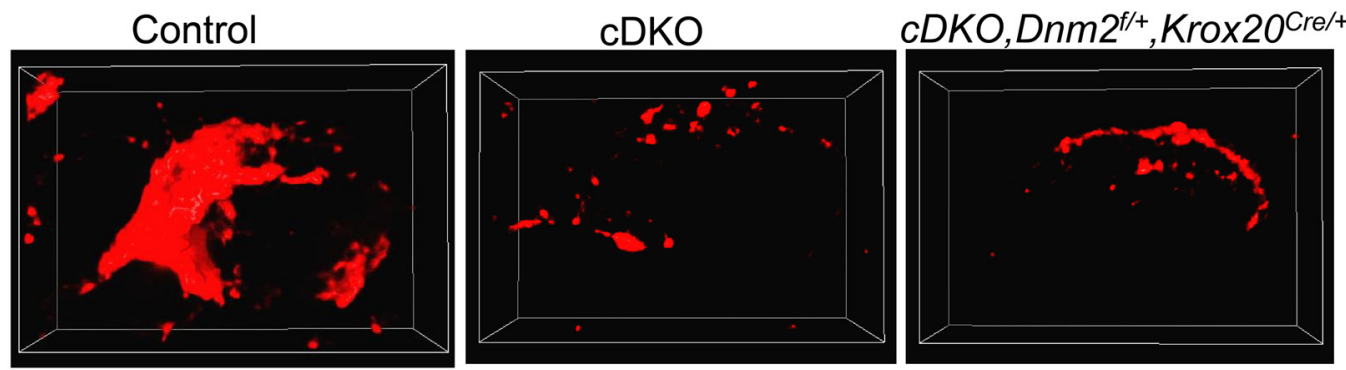

$\mathbf{F}$
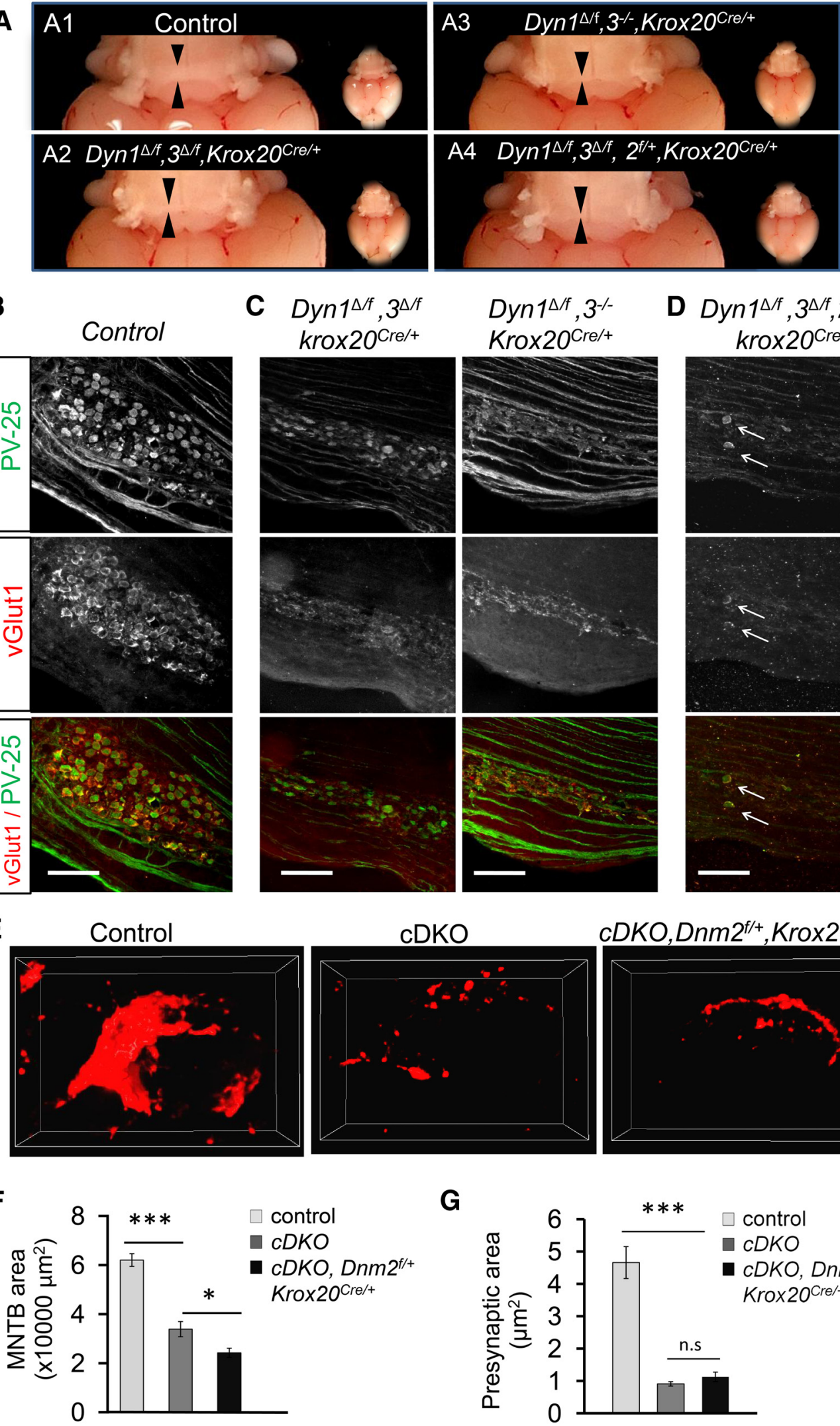

Dyn14/f, $3^{-/-}$

Krox $20^{\mathrm{Cre} /+}$

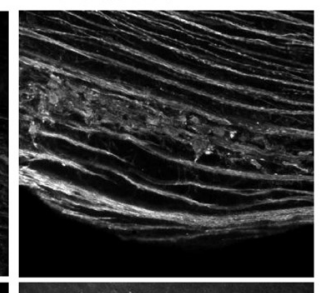

D $D y n 1^{\Delta / f}, 3^{\Delta / f}, 2^{f /+}$
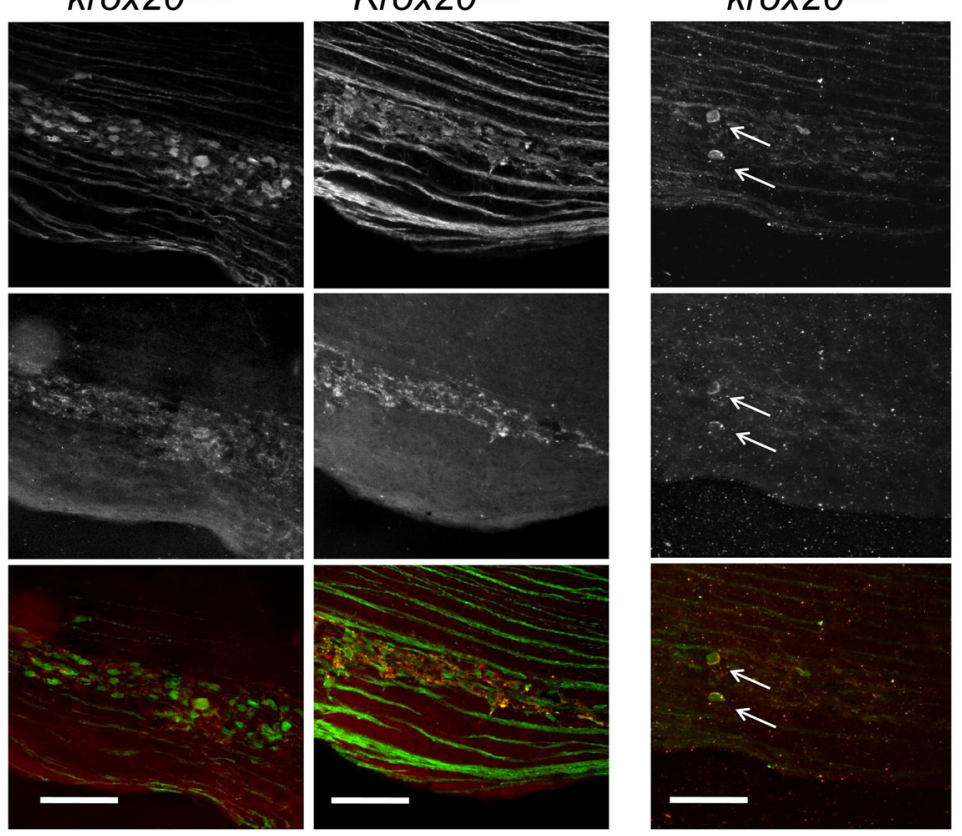

G

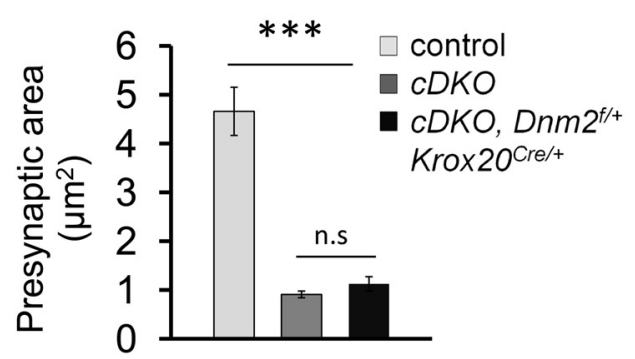

Figure 3. Different combinations of tissue-specific gene deletions in dynamin isoforms revealed gene dosage dependence of $\mathrm{CH}$ formation. $\boldsymbol{A}$, Visual appearance of the ventral auditory brainstems at P10 with different combinations of CKO of three dynamin isoforms (see Materials and Methods). Arrowheads indicate the width of axon bundles crossing the midline of auditory brainstems. A4, The axon bundle was barely visible, which carried only a single copy of dynamin 2. Right panels, Similar brain sizes and structures. B-D, MNTBs identified by vGlut1 and PV-25 fluorescence from P10 mice with different combinations of dynamin CKO. Note the gene dose-dependent decrease of MNTB and CH formation in MNTBs. Arrows indicate the occasionally observed calyx-like structures, which were positive for both vGlut1 and PV-25. Scale bar, $100 \mu \mathrm{m}$. $\boldsymbol{E}$, Representative 3D structures of presynaptic terminals from (Figure legend continues.) 
Combined conditional deletions of different dynamin isoforms reveal gene dose-dependent impairment in $\mathrm{CH}$ and MNTB development

To examine whether redundant functions of multiple dynamin isoforms mask the impact of endocytosis on $\mathrm{CH}$ development, we generated $\mathrm{cKO}$ mice with different combinations of dynamin isoforms. Dynamin 1 and 3 are dominant isoforms in neurons and enriched primarily at nerve terminals where they support synaptic endocytosis (Gray et al., 2005; Ferguson et al., 2007). Therefore, we focused on dynamin 1 and 3 conditional double $\mathrm{KO}$ (cDKO). In contrast to the conventional dynamin 1 and 3 double $\mathrm{KO}$ mice, which had limited movement and died within a few hours after birth (Raimondi et al., 2011), cDKO mice were viable but had a much lower fertility rate than control. They had smaller body size, often exhibited hunchback posture, and did not respond to normal sound stimulation. The axon bundle (between the black arrowheads) in the trapezoid body was thinner in $\mathrm{cDKO}$ than the control (Fig. 3). Likewise, the $\mathrm{cDKO}$ mice that were generated with a different approach $\left(D n m 1^{f / \Delta}\right.$, $3^{-/-}$, Krox $20^{+/ C r e}$; see Materials and Methods) exhibited a similar phenotype (Fig. 3A3). Further conditionally deletion a single copy of dynamin 2 led to a nearly invisible axon bundle on the brainstem surface (Fig. 3A4).

Immunohistochemistry at P8-P10 showed smaller MNTB areas, and weaker vGlut1 and PV-25 fluorescence in CDKOs than controls (Fig. $3 B-D$ ). Similar results were obtained using different presynaptic vesicle markers, such as synaptotagmin-2, vesicular glutamate transporter 2 (vGlut2), and synaptophysin. These data indicate a large decrease in synaptic vesicle number and terminal size in combined dynamin KOs. Furthermore, conditional deletion of a single copy of dynamin 2 on the background of cDKO led to barely visible MNTBs with very faint fluorescence (Fig. 3D). The CHs were only occasionally observed in $\mathrm{cDKO}$ and cDKO plus dynamin 2 heterozygous slices, and their structures were largely different from control (Fig. 3E). Quantitative analysis revealed dynamin gene dose-dependent decreases in the size of MNTB areas (Fig. 3F). The areas of presynaptic terminals were evaluated by presynaptic marker vGlut1, and they were significantly smaller in combined dynamin cKOs than controls (Fig. $3 G)$. These data, together with single cKO data described above, revealed a crucial function of dynamin 1 and 3 in $\mathrm{CH}$ development, as well as a certain level of their functional redundancy.

In the absence of dynamin 1 and 3, synaptic transmission still occurs despite its lower capacity and strongly decreased release probability (Raimondi et al., 2011; Lou et al., 2012). In an attempt to study dynamin conditional triple $\mathrm{KO}$ mice (cTKO) with all three dynamin isoforms selectively deleted in the auditory brainstem, cTKO pups died within a few hours after birth (data not shown). The severe endocytosis defect may impair the minimal synaptic activity or the early neural development required for essential function, such as the function of respiration center that also expresses Krox20Cre (Chatonnet et al., 2007). Interestingly, pups harboring only a single copy of Dnm2 gene in auditory brainstem $\left(D y n 1^{\Delta / f}, 3^{\Delta / f}, 2^{+/ f}\right.$, Krox20Cre ${ }^{+}$) survived (Fig. 3A4,D), but the MNTBs were even smaller $(p<0.05)$, disorganized and

\section{$\leftarrow$}

(Figure legend continued.) wild-type and those occasionally observed in dynamin KOs. $\boldsymbol{F}$, Average sizes of MNTB areas ( $n=10, n=6, n=5$ slices from 3 or 4 mice in each genotype). $\mathbf{G}$, Average sizes of presynaptic terminals as indicated by the vGlut1 fluorescence in a single optical section (total 350, 1015, and 203 nerve terminals from 4 MNTB regions in each genotype were collected under the $100 \times$ oil objective). ${ }^{*} p<0.05$. ${ }^{* *} p<0.005$. n.s, Not significant. with very weak vGlut1 fluorescence (Fig. $3 D, F$ ) compared with $\mathrm{cDKO}$. Therefore, dynamin $2 \mathrm{cKO}$ further exacerbates the $\mathrm{CH}$ developmental defect of $\mathrm{cDKO}$, despite its lower expression level in neurons and its lower efficiency in synaptic vesicle endocytosis (Ferguson et al., 2007; Ferguson and De Camilli, 2012). The potential defect in early neural development may also be involved in this case (Ferguson et al., 2009), in addition to the severe synaptic endocytosis defect. These data suggest an additive effect of different dynamin isoforms during $\mathrm{CH}$ development, in which the total amount of dynamin, in addition to their isoform-specific function (Liu et al., 2011; Ferguson and De Camilli, 2012), appears equally critical when the total dynamin level is low.

\section{Impaired $\mathrm{CH}$ morphological development at different postnatal days in the absence of dynamin 1 and 3}

During $\mathrm{CH}$ development, fast morphological remodeling is nearly complete within the first postnatal week. The diminished $\mathrm{CH}$ observed at P8-P10 in cDKO could arise from impaired calyx formation or $\mathrm{CH}$ retraction after protocalyx formation due to insufficient synaptic activity. To distinguish these two possibilities, we examined the $\mathrm{CH}$ development at different postnatal days. In control slices, protocalyces were visible at P3 and grew rapidly in the next few days, accompanied by a significant expansion of MNTB areas (Fig. 4). This is consistent with previous studies (Hoffpauir et al., 2006; Soria Van Hoeve and Borst, 2010; Holcomb et al., 2013). However, no significant increase of the MNTB area was observed in cDKO mice; the majority of small boutons in P1-P3 appeared not grow into calyx-type structures (Fig. 4A-C), and only a few calyces were occasionally observed in the MNTBs at P8 in cDKO (Fig. 4C, arrowheads). The growth curves of MNTB areas (Fig. 4D) were not significantly different before P3. However, they diverged after P3, a time point when most calyces start to form and grow rapidly. These results demonstrate that $\mathrm{CH}$ formation and growth require vigorous endocytosis mediated by dynamin 1 and 3 .

DiI tracing experiments from unilaterally labeled VCN at P10 showed abundant, DiI-labeled axon fibers crossing the brainstem middle line in wild types, and many calyceal terminals were clearly labeled in contralateral MNTBs (Fig. 4E,F). The cDKO slices also showed similar DiI-labeled axons from VCN to contralateral MNTB, but MNTB mainly contained small DiI-labeled puncta (Fig. 4F, right). A few calyces (arrows) were also visible sometimes, a scenario similar to Figure $4 C$ using PV-25 and vGlut1 fluorescence imaging. These data suggest MNTBs still receive abundant VCN innervations in $\mathrm{CDKO}$, although some noncalyceal excitatory inputs may also be present as reported in rat brainstems (Hamann et al., 2003).

Representative high-magnification images in Figure $5 A, B$ demonstrated the detailed morphological changes of $\mathrm{CH}$ and MNTB neurons in P8 cDKO mice. In contrast to numerous $\mathrm{CH}$ with strong vGlut fluorescence in control, cDKO had abundant, small, and puncta-like terminals but few typical CH (arrow). Moreover, vGlut1 fluorescence was much weaker than control, suggesting a limited number of synaptic vesicles in these terminals. PV-25 was strongly upregulated in MNTB neurons during synaptic development and maturation (Felmy and Schneggenburger, 2004). However, PV-25 fluorescence was much dimmer in $\mathrm{CDKO}$ than control, consistent with diminished synaptic activity. Quantitative analysis of high-resolution vGlut1 images with a binary mask (Fig. $5 C$ ) revealed a significant difference in presynaptic areas between control and $\mathrm{CDKO}$ during the first 3 postnatal weeks (Fig. 5D). The control terminal size increased rapidly during $\mathrm{P} 3-\mathrm{P} 5$ due to $\mathrm{CH}$ formation, and decreased during 

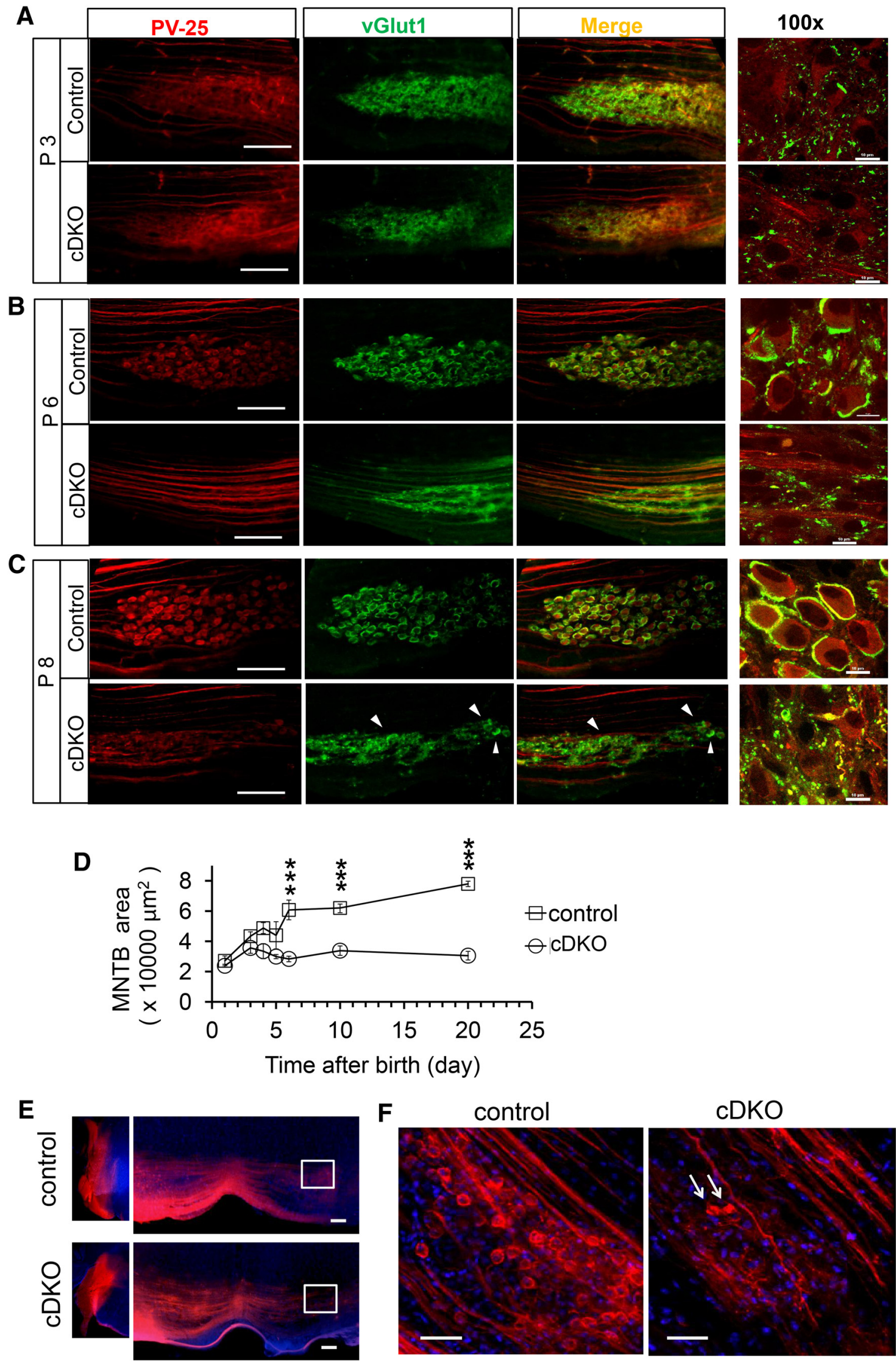

Figure 4. Developmental changes of MNTB and $C H$ between control and $C D K 0$ mice. $A-C$, Developmental changes in $C H$ and axon bundle visualized by vGlut 1 and PV-25 at P3 $(\boldsymbol{A})$, P6 (B), and P8 (C) under low (20×, left) and high magnification (100 $\times$, right). Note the differences between control and CDK0 at P6 and P8, but not at P3. C, Arrowheads indicate a few calyx-like structures in cDK0 MNTBs. Scale bars: $20 \times$ panels, $100 \mu \mathrm{m} ; 100 \times$ panels, $10 \mu \mathrm{m}$. D. Average size of MNTBs in control and CDK0 mice at different postnatal days. Four to 10 slices were examined from 3-5 mice for each age and genotype. Note the rapid separation of the curves after P3. E, Images of Dil fluorescence in P10 brainstems in control and cDK0 mice. Dil crystals (Figure legend continues.) 
maturation at $\sim \mathrm{P} 20$ resulting from further compartmentalization of $\mathrm{CH}$ (Fig. $5 D, E)$. In contrast, cDKO only slightly increased in size because of the impaired $\mathrm{CH}$ formation (Fig. $5 D, F$ ).

\section{Lack of both dynamin 1 and 3 does not affect initial} synaptogenesis of $\mathrm{CH}$ but influences synapse maintenance We next examined whether the loss of dynamin affects initial synapse assembly of CH before protocalyx formation. Synaptogenesis begins with growth cone contacts with the postsynaptic partners and followed by subsequent recruitment of key synaptic components, such as presynaptic vesicles, AZs, and PSD proteins (McAllister, 2007). The GBC growth cones cross brainstem midline at E14.5 in mice (Howell et al., 2007) and could make functional connections with MNTB neurons at $\sim$ E17 (Hoffpauir et al., 2010). These synaptic puncta increasingly elaborate into protocalyces at $\sim \mathrm{P} 3$ and abruptly complete their fast growth in the next 2-3 d (P3-P5) (Hoffpauir et al., 2006; Soria Van Hoeve and Borst, 2010; Holcomb et al., 2013). We examined the CH synaptogenesis using specific antibodies against vGlut1, Bassoon, and PSD95 as indicators to identify three key synaptic components: vesicles, AZs, and the apposed PSDs, respectively (Fig. 6A).

Both control and cDKO MNTBs showed abundant fluorescence puncta at P1, most of which had all three synaptic components at this stage (Fig. $6 B, C$ ). The enlarged views of puncta showed the typical glutamatergic synaptic structure: PSDs and AZs, which were adjacent to a cluster of synaptic vesicles (Fig. $6 \mathrm{~B}, \mathrm{C}$, right panels). In addition, some fluorescence puncta only contained one or two synaptic components, indicating the presence of different stages of early synaptic assembly in both control and $\mathrm{cDKO}$ (Fig. $6 \mathrm{~B}, \mathrm{C}$, arrows and arrowheads). These data suggested a similar occurrence of synaptic assembly in $\mathrm{CDKO}$ as in control. Quantitative analysis of vGlut1 signals suggested a comparable size of presynaptic terminals between $\mathrm{CDKO}$ and control at P1 (Fig. 6D), and synaptic densities marked by vGlut1 or Bassoon were not significantly different between the two groups $(p>0.05)$ (Fig. 6E,F). Thus, lack of dynamin 1 and 3 does not significantly affect initial synaptic assembly in MNTBs at P1, a time period when synaptic activity and transmitter release were low (Hoffpauir et al., 2006; Xiao et al., 2013).

Similarly, we observed a comparable synaptic morphology at $\mathrm{P} 3$ between $\mathrm{CDKO}$ and control, and slightly larger puncta in control were only occasionally observed. At P5, many newly formed $\mathrm{CHs}$ in control had abundant synaptic vesicles, AZs, and the apposed PSDs. These structures often covered a large part of their target neurons (Fig. 6G,H, top), in agreement with a rapid $\mathrm{CH}$ growth by P5 in mice (Holcomb et al., 2013). In contrast, only a very limited number of $\mathrm{CHs}$ were observed in $\mathrm{cDKO}$ at the same age; they often had much smaller size and weaker vGlut 1 fluorescence, and discretely distributed around MNTB neurons (Fig. $6 G, H$, bottom). The weaker vGlut1 fluorescence in these terminals suggests less abundant vesicles. These data suggest that the loss of dynamin 1 and 3 prevents $\mathrm{CH}$ assembly in vivo.

Because the $\mathrm{CH}$ continually refines its structure until adulthood (Taschenberger et al., 2002; Wimmer et al., 2006), we therefore examined the mature $\mathrm{CH}$ structures at $\mathrm{P} 20$. In contrast to control, cDKO MNTBs at this age were much smaller and disor-

\section{$\leftarrow$}

(Figure legend continued.) were applied unilaterally in the $\operatorname{VCN}(\boldsymbol{E}$, left). $\boldsymbol{F}$, Highmagnification images of Dil-labeled axon fibers and nerve terminals in contralateral MNTB regions (squares). Note the abundant small puncta in the CDKO MNTB, except for a few $\mathrm{CH}$ structures (arrows). Scale bars: $\boldsymbol{E}, 100 \mu \mathrm{m} ; \boldsymbol{F}, 50 \mu \mathrm{m} .{ }^{* * *} p<0.005$. ganized (Fig. 7A), and they showed progressive neurodegeneration and neuron loss (Fig. 7A, inset). A few large nerve terminals revealed by different synaptic markers showed aberrant morphology in cDKO (Fig. 7B,C). They exhibited variable sizes in AZs and PSDs, dim vGlut1 fluorescence, misaligned AZs and PSDs, and loss of some synaptic components. The relative abundance and locations of three synaptic components are highlighted in Figure 7C. For example, some synaptic structures contained weak vGlut1 and completely lacked AZ fluorescence (Fig. 7C3). The large terminals identified by ring-shaped vGlut1 fluorescence had no postsynaptic neurons (Fig. $7 A$, inset), presumably reflecting different extents of $\mathrm{CH}$ degeneration and MNTB neuron loss at this developmental stage. Along this direction, GFAP immunostaining in MNTB revealed a much stronger astrocyte signal in control than cDKO starting at P10 (Fig. 7D). Microglia, as revealed by Ibal fluorescence, were also more abundant (Fig. 7E) and had different morphology (fatter and shorter processes) (Fig. $7 F$ ) in the $\mathrm{CDKO}$, suggesting microglia activation (Kettenmann et al., 2011). The astrocyte infiltration and microglial activation in $\mathrm{CDKO}$ were consistent with their roles in synaptic pruning and debris clearance (Barres, 2008), indicating ongoing neurodegeneration and neuron loss.

\section{Dynamin 1- and 3-mediated endocytosis is required for functional maturation of synaptic transmission in vivo}

Next, we assessed how the lack of dynamin 1 and 3 affects synaptic transmission in MNTBs. As we showed above, cDKO mice had much smaller nerve terminals in MNTBs; the calyx-like structures that were occasionally observed using fluorescence microscopy were invisible under the DIC microscope in the acute slices. This prevented us from performing routine presynaptic capacitance recording from $\mathrm{CH}$ (Lou et al., 2008b). Unlike in normal slices, even when we tried to record EPSCs by stimulating afferent fibers (Lou et al., 2008a), no responsive neurons in cDKO MNTBs could be identified. Finally, direct recordings from CDKO MNTB neurons without prescreening responsive neurons failed to produce evoked EPSCs. Because MNTB neurons were still innervated by axons from VCN (Fig. $4 F$ ), this result likely reflects some technical difficulty: CDKO EPSCs might be too small to be easily detected with this approach. This is consistent with the observations of much smaller terminals and much weaker vGlut1 fluorescence in cDKO (Fig. 5) than control; accordingly, EPSC amplitude decreased $\sim 10 \times$ in conventional DKO neuronal cultures due to vesicle depletion and decreased release probability (Raimondi et al., 2011; Lou et al., 2012).

To bypass these technical problems and probe synaptic transmission in cDKO, we recorded sEPSCs from neurons in MNTBs. Figure $8 A-D$ shows representative experiments from MNTB neurons at P10. The amplitude distributions of individual sEPSC events were skewed in both cases (Fig. 8B), and the cumulative probability curve in $\mathrm{CDKO}$ was marginally shifted to the right (Fig. $8 B$, inset). The average sEPSC amplitude (cell mean) of cDKO neurons was only slightly bigger than control (41.9 \pm 37 and $48.3 \pm 5.9 \mathrm{pA}$ for control and $\mathrm{cDKO}, n=12$ neurons in each group; $p=0.37$ ) (Fig. $8 E$ ), but the average charge of sEPSCs was significantly larger than control $(p=0.014)$ (Fig. $8 F)$. Moreover, sEPSC frequency in cDKO was smaller $(p=0.043, n=12$ cells in each group) (Fig. $8 C, G$ ). Individual sEPSCs (100 events each for both control and $\mathrm{cDKO}$ recordings) showed slower kinetics in cKO synapses (Fig. $8 D$ ), and quantitative analysis of sEPSCs demonstrated significant slowing in average rise time, decay time, and half-width in $\mathrm{cDKO}$ (Fig. $8 \mathrm{H}$; Table $1 ; n=12$ for each group). The functional acceleration of synaptic transmission is an 
A

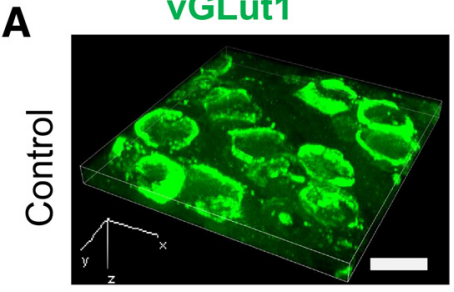

B

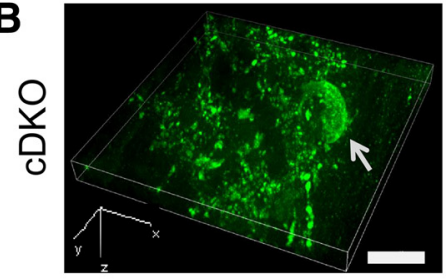

PV25
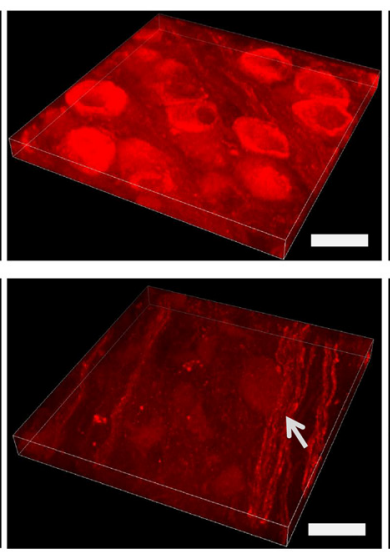

Merge
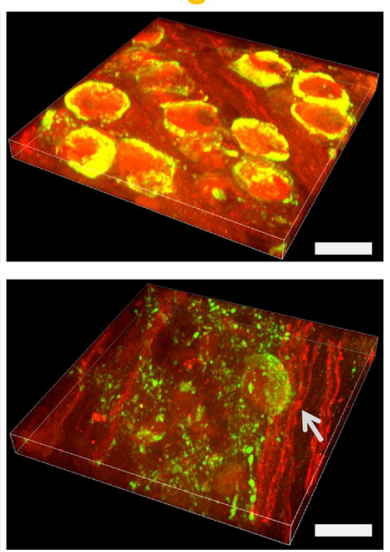

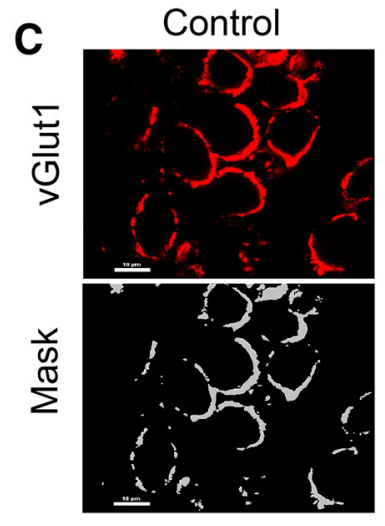

E

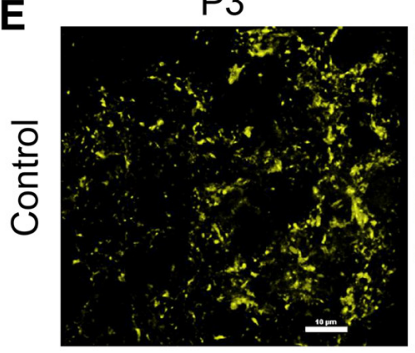

F

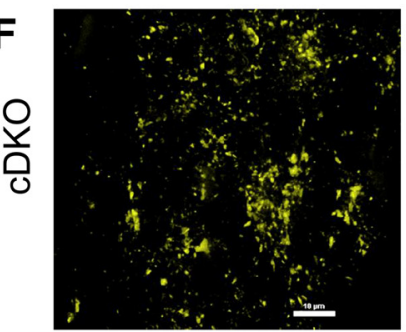

cDKO

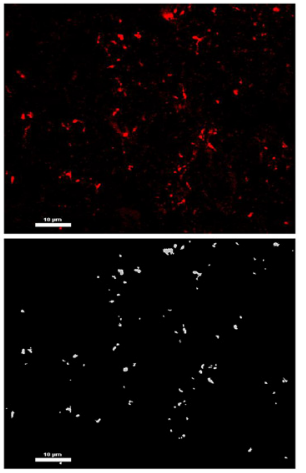

D

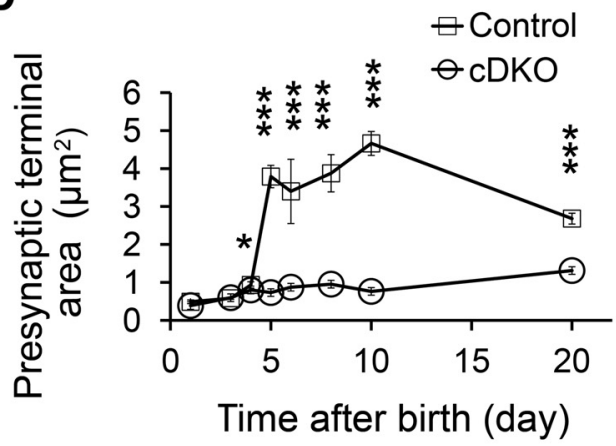

P5
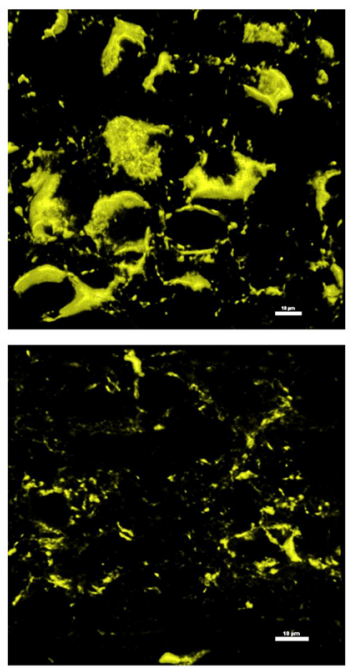

P8-10
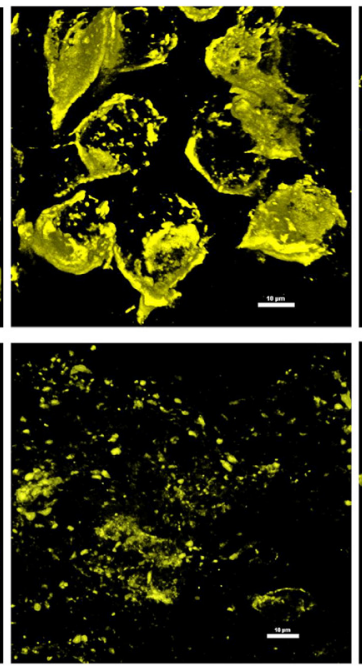

P20
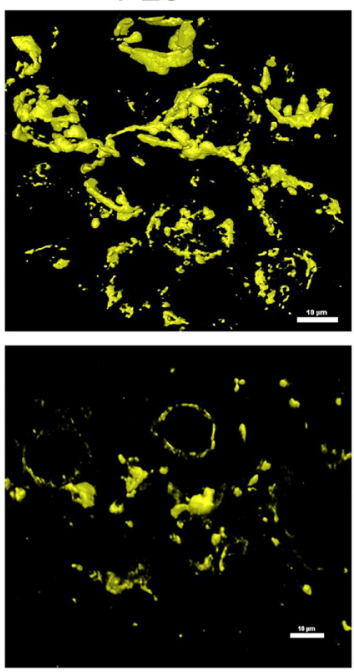

Figure 5. Impaired $\mathrm{CH}$ formation during development in CDKO mice. $A, B, 3 \mathrm{D} C \mathrm{CH}$ structures of the small MNTB regions of P8 mice detected by vGlut1 and PV- 25 immunofluorescence. Note the much smaller size of terminals and weaker PV-25 signals in CDKO than control. Arrow indicates a faintly labeled $C H$. The images were displayed at the same settings for control and $C D K 0$. C, Analysis of the presynaptic area under confocal sections of P10 MNTBs with a binary mask of vGlut1 fluorescence. D, Developmental changes in presynaptic terminal areas in control and $C D K O$ ( $n=4-16$ MNTB regions from at least 2 mice in each age and genotype were collected $<100 \times)$. $E, F$, Structures of presynaptic terminals in MNTBs at different postnatal days in control and $C D K 0$. Volume view of each region was acquired and reconstructed through serial confocal sections under a $100 \times$ oil lens. Note the rapid appearance of giant cycles at P5 in control, but not in cDKO. Scale bars: $A, B, 20$ $\mu \mathrm{m} ; \boldsymbol{C}, \boldsymbol{E}, \boldsymbol{F}, 10 \mu \mathrm{m} .{ }^{*} p<0.05$. $^{* *} p<0.005$.

important developmental property at the calyx of Held (Taschenberger and von Gersdorff, 2000), resulting from postsynaptic AMPA receptor switching from glutamate receptor subunit 1 (GluR1) to the fast gating subunit 4 (GluR4) flop (Joshi et al., 2004; Koike-Tani et al., 2005). The slower sEPSC kinetics in
cDKO suggests a developmental delay or deficiency in postsynaptic AMPA receptors. This change partly explains the significant increase in sEPSC charge but not amplitude in cDKO.

To examine developmental properties of synaptic transmission, we measured sEPSCs at P4, a time point when synaptic 
A
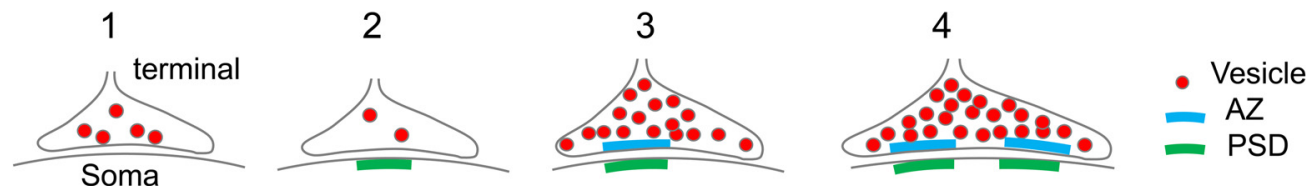

B P1 Control (vGlut1/Bassoon/PSD95/DAPI)
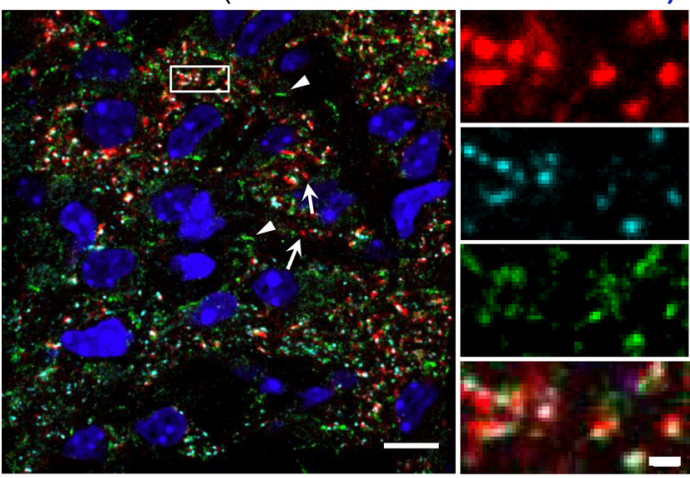

C P1 cDKo

(vGlut1/Bassoon/PSD95/DAPI)
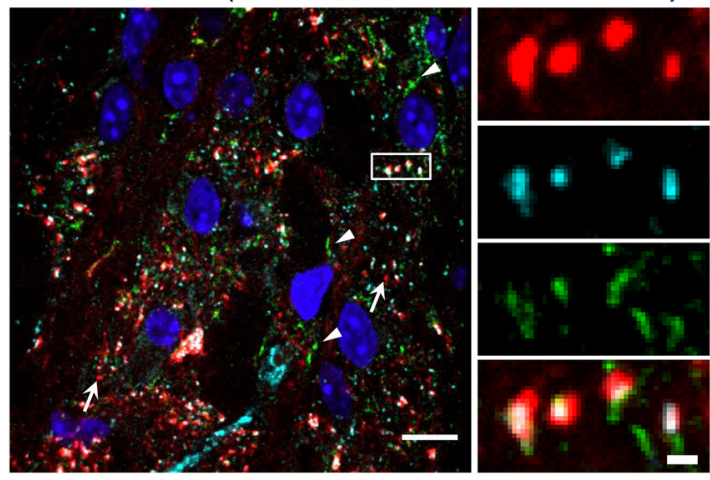

D

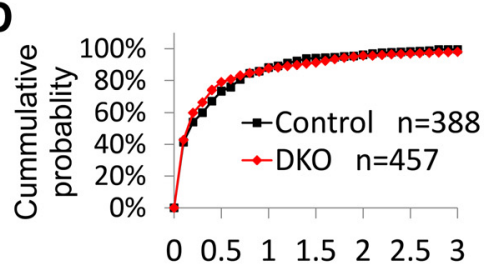

vGlut-1 puncta area $\left(\mu \mathrm{m}^{2}\right)$
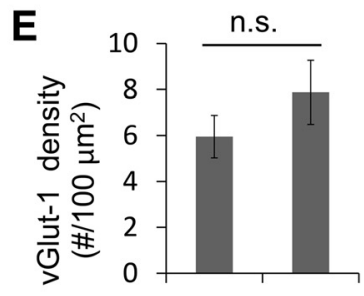

Control CDKO
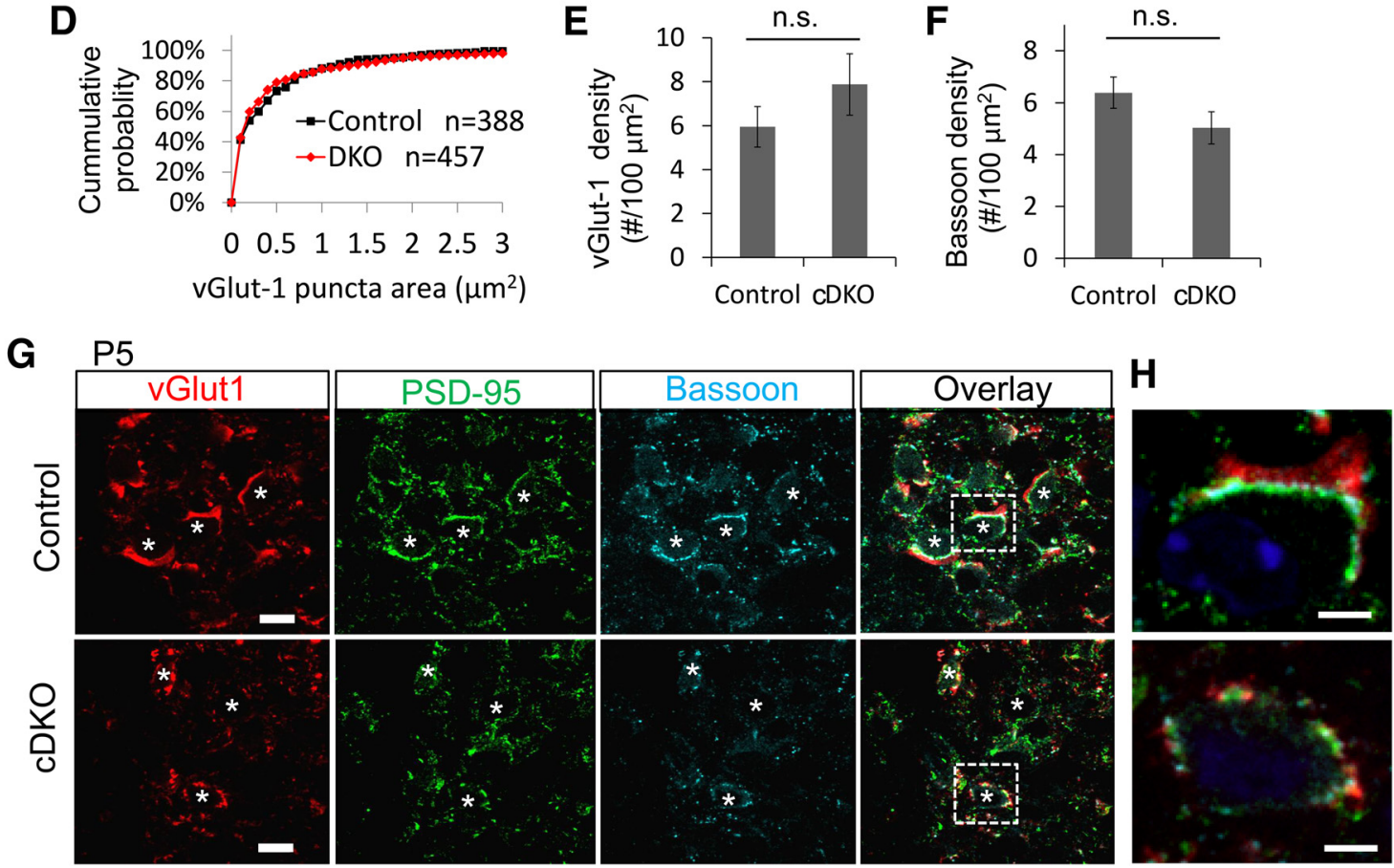

Figure 6. Different effects of conditional deletion of dynamin 1 and 3 on synaptogenesis and $C H$ formation. $A$, Diagram illustration of the initial synapse assembly under different conditions before protocalyx formation in MNTB. B, C, Representative images of small synaptic puncta in P1 control and CDKO MNTBs. We visualized excitatory synaptic vesicles, AZs, and postsynaptic density with VGlut1 (red), Bassoon (cyan), and PSD-95 (green) antibodies, respectively. Nuclei were labeled with DAPI (blue). Right, Enlarged views of individual synapses (a boxed region). The cluster of vesicles often colocalized with AZ and PSD; the different synaptogenesis stages as illustrated in $A$ can be identified in both control and $C D K O(B, C$. Arrows and arrowheads indicate the puncta missing one or two other synaptic markers. $\boldsymbol{D}$, Cumulative plot of individual vGlut1 puncta area from a representative MNTB slice from P1 control $(n=388)$ and $C D K O(n=457$ terminals), respectively. $\boldsymbol{E}$, $\boldsymbol{F}$, The average density of $v G l u t 1(\boldsymbol{E})$ and Bassoon $(\boldsymbol{F})$ puncta $(n=4$ MNTB regions in each genotype, $p>0.05)$. G, Representative MNTB images from P5 control and $c D K 0$ mice. A very limited number of calyx terminals were observed in CDKO. $\boldsymbol{H}$, Enlarged views of the boxed areas in $\boldsymbol{G}$. The weak vGlut1, discrete AZs, and PSDs in CDKO compared with the controls where AZs and PSDs were nicely apposed next to abundant presynaptic vesicles. Scale bars: $\boldsymbol{B}, \boldsymbol{C}$, left, $\boldsymbol{G}, 10 \mu \mathrm{m} ; \boldsymbol{B}, \boldsymbol{C}$, right, insets, $1 \mu \mathrm{m} ; \boldsymbol{H}$, insets, $4 \mu \mathrm{m}$. n.s., Not significant.

transmission just starts to develop. As expected, sEPSC kinetics at P4 was much slower than at P10 in wild-type (Fig. 8I), in agreement with the rapid developmental acceleration of synaptic transmission at the $\mathrm{CH}$ (Taschenberger and von Gersdorff, 2000). Quantitative analysis revealed significant changes in sEPSC properties at P9-P10 ( $n=12$ neurons) over P4-P5 ( $n=14$ neurons) (Fig. $8 \mathrm{~K}$; Table 1 ) in wild-types, such as decreases in amplitude and charge, and acceleration of kinetics. However, such developmental changes were nearly absent in cDKO syn- apses (Fig. 8J), and no obvious developmental acceleration in sEPSCs was observed at P9-P10 $(n=12)$ over P4-P5 $(n=16)$ (Fig. $8 K$; Table 1 ). These data indicated that dynamin $1-$ and 3-mediated endocytosis is required not only for structural development but also for functional maturation of central synapses in vivo.

We further compared the membrane excitability of MNTB neurons between control and cDKO. Whole-cell voltage-clamp recordings showed similar properties of voltage-gated ion chan- 
A vGlut1/Bassoon/PSD95/DAPI
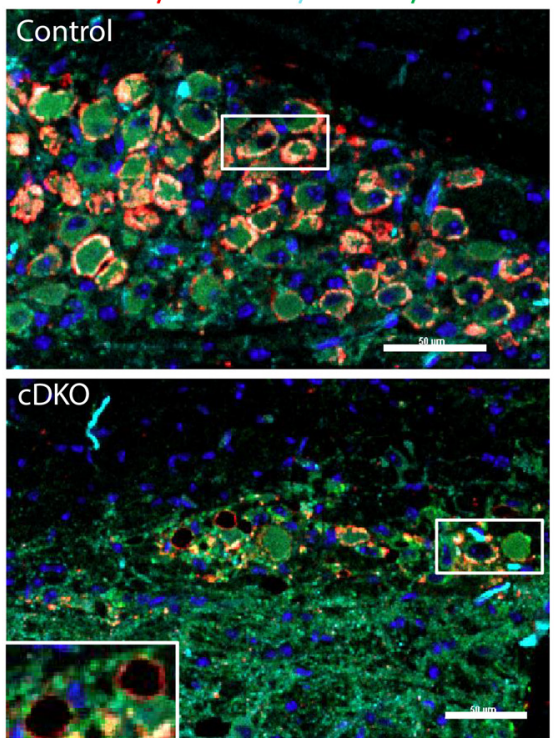

B
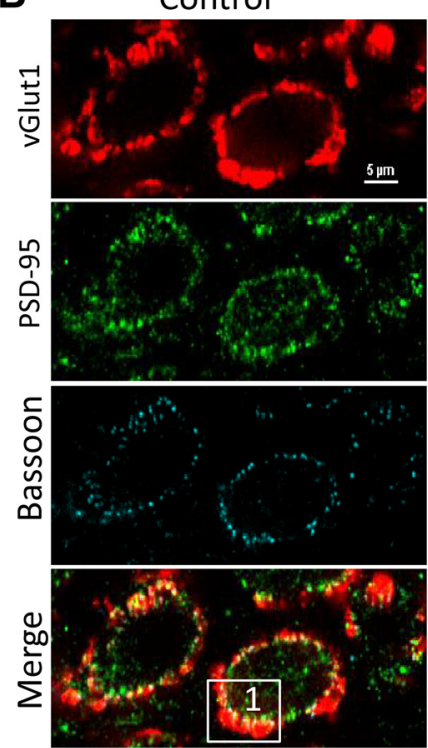

CDKO
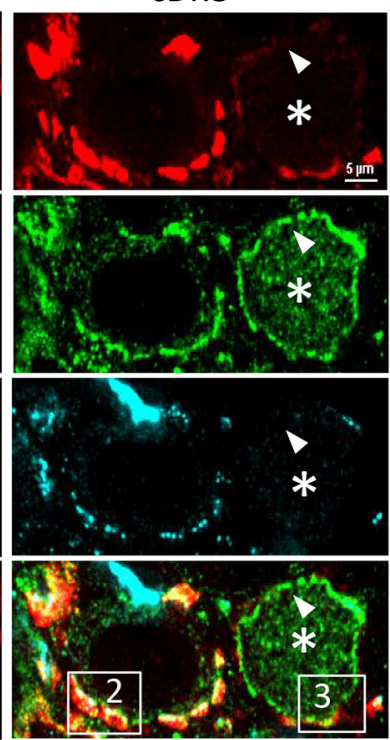

C
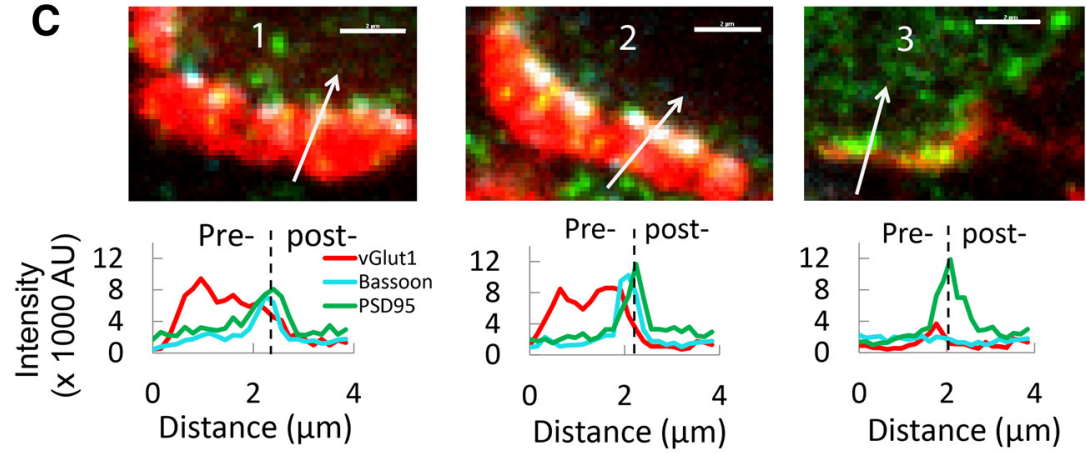

D

P3

P5

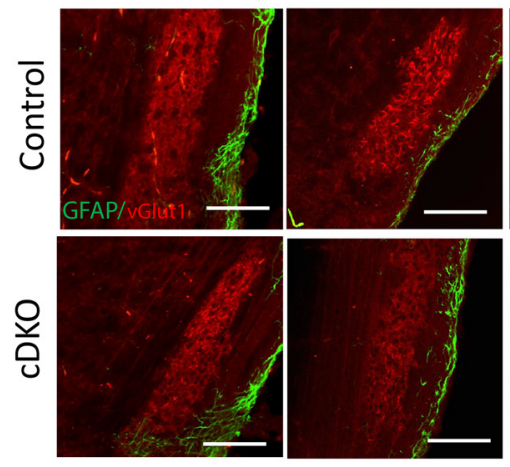

P10
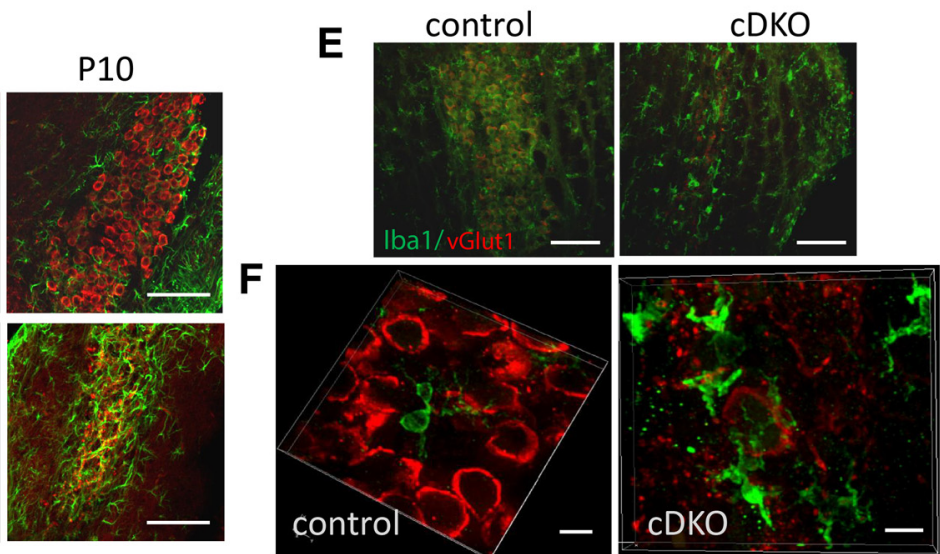

Figure 7. Morphological changes of $\mathrm{CH}$ in control and cDKO after hearing onset. $A$, Low-resolution images of MNTB at P2O from control (top) and cDKO mice. Note the smaller MNTB area and less CH and MNTB neurons in CDKO. B, High-resolution images of two calyces from the boxed regions in $A$. Note the aberrant synaptic structures in cDK0. *Neuron with strong PSD-95 staining but much weaker vGlut1 and Bassoon signals (arrowhead). $\boldsymbol{C}$, Enlarged views of the $\mathrm{CH}$ fine structures in $\boldsymbol{B}$. The fluorescence intensity profiles and relative position of synaptic vesicles (red), AZs (cyan), and PSDs (green) along the white lines are shown below. Dashed line indicates the synaptic cleft position. $\boldsymbol{D}$, Increased number of astrocytes revealed by GFAP fluorescence in MNTB from cK0 than control at P10 (but not by P5). $\boldsymbol{E}, \boldsymbol{F}$, Activation of microglia in CDKO MNTBs at P10 revealed by the anti-lba1 antibody. Iba1 fluorescence in control and CDKO MNTBs $<20 \times$ microscopy $(\boldsymbol{E})$ and the fine structures of microglia $(\boldsymbol{F}, 3 \mathrm{D}$ reconstructions $<100 \times)$. Scale bars: $\boldsymbol{A}, 50 \mu \mathrm{m} ; \boldsymbol{B}, 5 \mu \mathrm{m} ; \boldsymbol{C}, 2 \mu \mathrm{m} ; \boldsymbol{D}, \boldsymbol{E}, 100 \mu \mathrm{m} ; \boldsymbol{F}, 10 \mu \mathrm{m}$.

nels in neurons at $\mathrm{P} 4$ between the two groups (Fig. 9A). Currentclamp recordings revealed higher membrane excitability in cDKO neurons than controls. None of 6 control neurons displayed spontaneous action potentials (APs), but 4 of $5 \mathrm{cDKO}$ neurons exhibited spontaneous APs at a frequency range of $0.2-7$ $\mathrm{Hz}(2.2 \pm 1.2 \mathrm{~Hz})$ (Fig. 9C) in brain slices. The resting membrane potential $\left(V_{r}\right)$ of $\mathrm{cDKO}$ neurons was significantly higher than controls at P3-P4, consistent with more frequent spontaneous APs. Upon current injections, $\mathrm{cDKO}$ neurons were prone to fire tonic APs with a higher frequency (Fig. 9E). At P5-P6, control neurons rarely fired tonic APs, except at the beginning of stimulation ( $n=5$ neurons). This is consistent with the AP pattern switching (from tonic to phasic) during the first postnatal week of MNTB development (Hoffpauir et al., 2010). In contrast, cDKO 
A

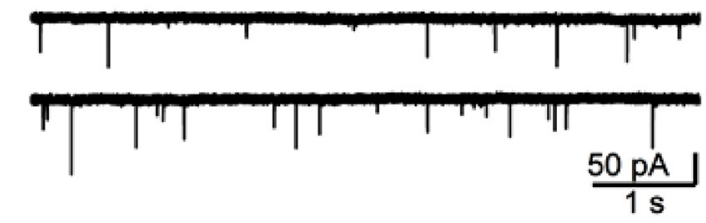

B

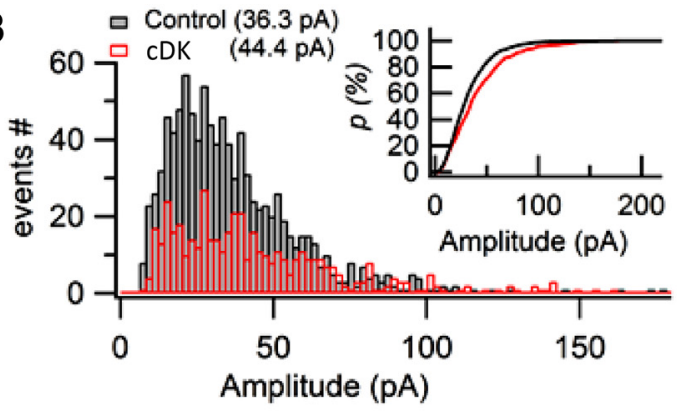

CDKO $(0.8 \mathrm{~Hz})$

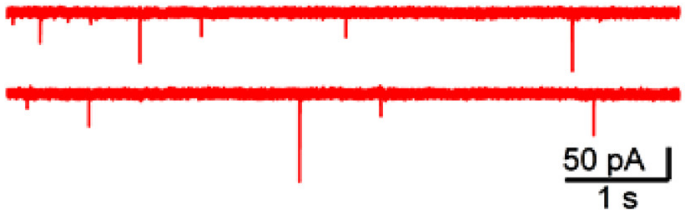

C

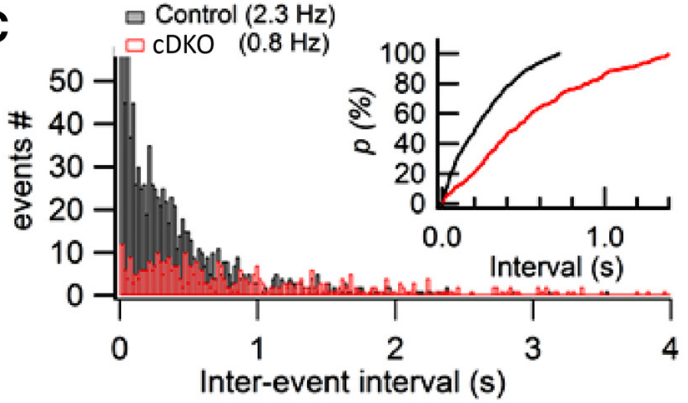

D

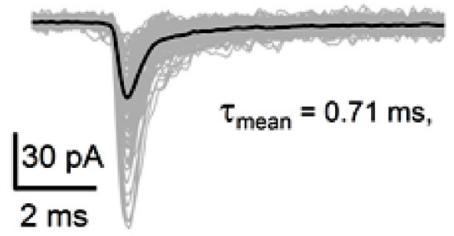

CDKO

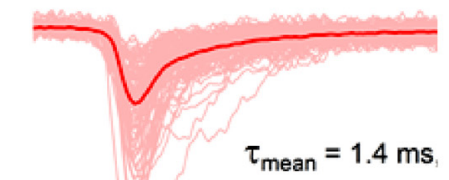

$\frac{30 p A}{2 m s}$

I

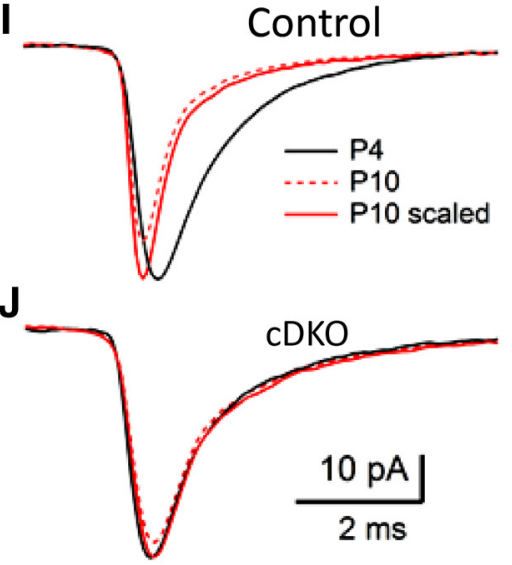

E

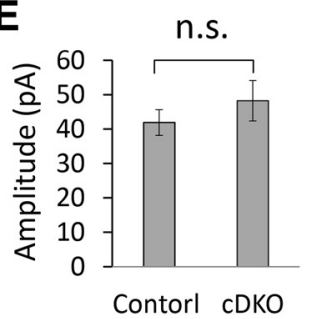

F

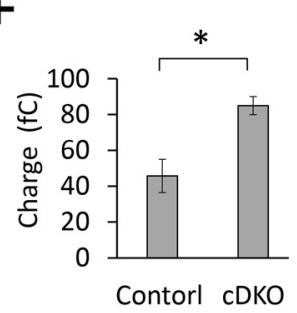

H

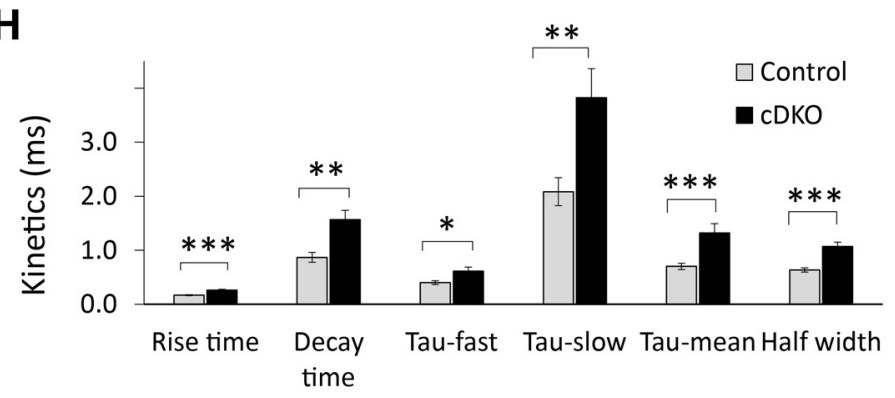

K

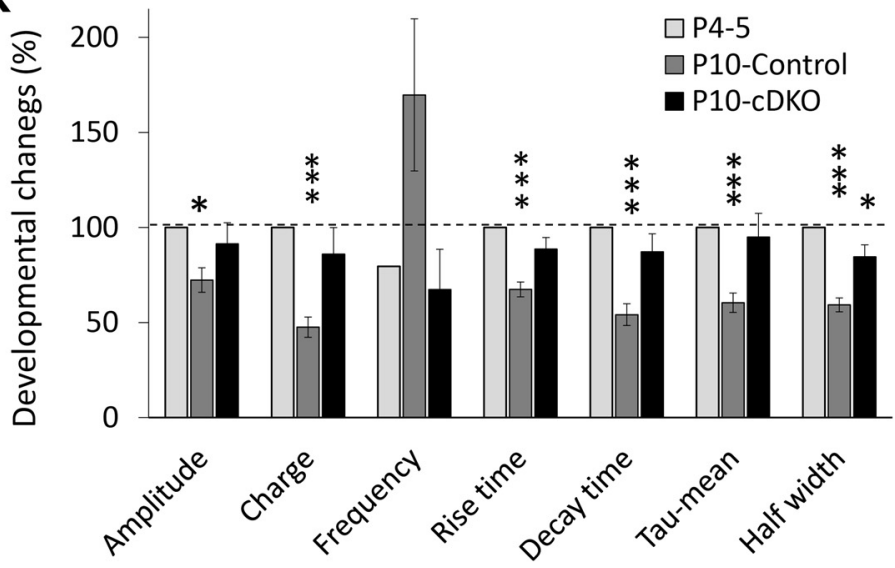

Figure 8. Impaired functional development of synaptic transmission in CDKOMNTB. $A$, Representative sEPSC recordings from an MNTB region of control and cDKO mice. The average frequencies from the cell shown were 2.3 and $0.8 \mathrm{~Hz}$ for control and CDK0, respectively. $\boldsymbol{B}$, Amplitude distributions of individual sEPSCsfrom the same cells shown in $A$ ( $n=869$ and $n=458$ events for control and cK0, respectively). Inset, Cumulative probability of sEPSC amplitudes. C, Similar to $\boldsymbol{B}$, distribution of interevent intervals of sEPSCS and their cumulative probability (inset). $\boldsymbol{D}$, Kinetics of sEPSCs recorded from $\boldsymbol{A}$. Individual sEPSC traces (lightertraces, $n=100$ for each cell) were realigned in time and superimposed with their average (solid trace) in each group. Notetheslower rise and decay ofsEPSCsin CDKO than control. $\boldsymbol{E}-\boldsymbol{H}$, Summary ofsEPSC amplitude $(\boldsymbol{E})$, charge transfer $(\boldsymbol{F})$, frequency $(\boldsymbol{G})$, and kinetics $(\boldsymbol{H})$ in control and CDK0 groups $(n=12$ neurons in each group). $\boldsymbol{I}, \boldsymbol{J}$, Different developmental changes of sEPSC kinetics between P4-P5 and P9-P10 in control ( $($ ) and CDKO (I) MNTB neurons. Black and red (dashed line) traces represent average SEPSCsfrom representative cells at the indicated age and genotype. Note the significant acceleration of 5 EPSC kinetics at P10 over P4 in control, but not in CDKO. $\boldsymbol{K}$, The relative changes (in percentage) of sEPSC amplitude, charge, frequency, and kinetics at P9-P10 MNTB ( $n=12$ neurons in each group) versus at P4-P5 ( $n=14$ and $n=16$ neurons for control and CDKO, respectively). ${ }^{*} p<0.05 .{ }^{* *} p<0.01 .{ }^{* * *} p<0.005$. n.s., Not significant. 
Table 1. The properties of $s E P S C s$ recorded in control and CDKO MNTN neurons at P4-P5 and P9-P10

\begin{tabular}{|c|c|c|c|c|}
\hline \multirow[b]{2}{*}{ Genotypes } & \multicolumn{2}{|l|}{ P4-P5 } & \multicolumn{2}{|l|}{ P9-P10 } \\
\hline & $\begin{array}{l}\text { Control } \\
(n=14)\end{array}$ & $\begin{array}{l}\text { CDK0 } \\
(n=16)\end{array}$ & $\begin{array}{l}\text { Control } \\
(n=12)\end{array}$ & $\begin{array}{l}\text { CDKO } \\
(n=12)\end{array}$ \\
\hline Amplitude (pA) & $57.9 \pm 4.5$ & $52.8 \pm 4.1$ & $41.9 \pm 3.7$ & $48.3 \pm 5.9$ \\
\hline Charge (pC) & $96.2 \pm 9.3$ & $98.9 \pm 7.7$ & $45.8 \pm 5.1$ & $85 \pm 13.8$ \\
\hline Frequency (Hz) & $1.34 \pm 0.38$ & $1.4 \pm 0.28$ & $2.27 \pm 0.53$ & $0.95 \pm 0.3$ \\
\hline $20 \%-80 \%$ rise $(\mu \mathrm{s})$ & $247 \pm 11$ & $293 \pm 10$ & $167 \pm 9$ & $259 \pm 17$ \\
\hline $20 \%-80 \%$ decay (ms) & $1.6 \pm 0.12$ & $1.8 \pm 0.06$ & $0.87 \pm 0.1$ & $1.6 \pm 0.17$ \\
\hline$t_{\text {-fast }}(\mu \mathrm{s})$ & $529 \pm 40$ & $780 \pm 51$ & $399 \pm 36$ & $613 \pm 74$ \\
\hline$t_{\text {-slow }}(\mathrm{ms})$ & $2.4 \pm 0.3$ & $3.2 \pm 0.3$ & $2.1 \pm 0.25$ & $3.8 \pm 0.54$ \\
\hline$t_{\text {mean }}(\mathrm{ms})^{a}$ & $1.16 \pm 0.1$ & $1.38 \pm 0.07$ & $0.70 \pm 0.06$ & $1.32 \pm 0.17$ \\
\hline Half-width (ms) & $1.07 \pm 0.06$ & $1.26 \pm 0.04$ & $0.63 \pm 0.04$ & $1.07 \pm 0.08$ \\
\hline
\end{tabular}

${ }^{a} t_{\text {mean }}$ is the weighted decay time constant of $\mathrm{SEPSCS}\left(t_{\text {mean }}=\mathrm{A}_{\text {fast }} t_{\text {fast }}+\mathrm{A}_{\text {slow }} t_{\text {slow }}\right)$, where $\mathrm{A}_{\text {fast }}$ and $\mathrm{A}_{\text {slow }}$ are the relative amplitudes of fast and slow decay components, respectively.

neurons frequently maintained their tonic AP firing properties ( $n=8$ cells) (Fig. $9 F, G)$, suggesting higher neuronal excitability in these neurons, which may compensate for the decreased synaptic activity in vivo.

\section{Discussion}

We systematically examined the development of $\mathrm{CH}$ after genetic perturbations of endocytosis using different tissue-specific gene deletions of multiple dynamin isoforms. Ablation of any single dynamin isoform (dynamin 1, 2, or 3) failed to alter $\mathrm{CH}$ development, but combined deletions of multiple dynamin isoforms showed an additive effect on $\mathrm{CH}$ development. Dynamin 1 and 3 cDKO severely impaired $\mathrm{CH}$ formation and growth starting from P3, accompanied with MNTB neuron loss and glial infiltration late in development. However, early synaptogenesis in MNTBs appeared normal. In parallel, developmental maturation of neurotransmission in MNTBs was impaired in CDKO. These findings provide direct genetic evidence that dynamin 1- and 3-mediated endocytosis is essential for $\mathrm{CH}$ development but not for initial synaptogenesis in vivo, implying an important role of endocytosis in CNS synapse development in the mammalian brain.

\section{Dynamin-mediated endocytosis regulates synapse development but not synaptogenesis in vivo}

Dynamin is critical for synaptic vesicle endocytosis at central synapses (Ferguson and De Camilli, 2012). Genetic studies reported an activity-dependent endocytosis defect in dynamin 1 KO synapses (Ferguson et al., 2007; Lou et al., 2008b); combined deletion of dynamin 1 and 3 worsens the endocytosis defect (Raimondi et al., 2011; Lou et al., 2012; Wu et al., 2014b). Here we showed that the combined dynamin deletions impair synapse development in the native brain circuitry, which parallels vesicle endocytosis and neurotransmission changes at $\mathrm{CH}$. Although deletions of individual dynamin isoforms do not affect $\mathrm{CH}$ development, their combined deletion additively aggravates $\mathrm{CH}$ developmental deficiencies (Fig. 3). Despite the functional specificity of individual dynamin isoforms (Liu et al., 2011; Ferguson and De Camilli, 2012), the gene dose-dependent exacerbation of aberrant $\mathrm{CH}$ development suggests some overlapping in vivo function of different dynamin isoforms, particularly between dynamin 1 and 3 .

Aberrant NMJ morphological development (i.e., abundant small supernumerary boutons) has been reported in Drosophila gene mutants involved in endocytosis, such as endophilin, synaptojanin, dynamin, AP180, synaptotagmin, and intersectin/ Dap160 (Koh et al., 2004; Marie et al., 2004; Dickman et al.,
2006). The current study extends the endocytosis function in synaptic development from peripheral nerve terminals into CNS synapses. Despite some phenotypic differences between $\mathrm{CH}$ (strong inhibition of $\mathrm{CH}$ formation in $\mathrm{cDKO}$ ) and NMJs (increased satellite NMJ formation in Drosophila mutants), these data indicate a conserved function of dynamin-mediated endocytosis in synaptic development across species.

The loss of dynamin 1 and 3 appears to not affect early synaptogenesis before the calyx formation (Fig. $6 A-F$ ). This is consistent with the intact synaptic density and neuron morphology observed in neuronal cultures from the conventional dynamin 1 and 3 DKO (Raimondi et al., 2011). The normal synaptogenesis in $\mathrm{CDKO}$ in vivo might simply reflect a low demand of vesicle endocytosis at this stage due to relatively weak neural activity and vesicle recycling; dynamin 2 in cDKO neurons presumably is sufficient for the low level of endocytosis before protocalyx formation. This is consistent with the notion that neural circuitry assembly primarily depends on intrinsic genetic signaling (Hiesinger et al., 2006; Sanes and Yamagata, 2009). In the auditory brainstem, the cellular signals mediated by Netrin/DDC (Howell et al., 2007), Eph/Ephrin (Hsieh et al., 2010), and Robo3 (Michalski et al., 2013) are important for proper synaptic innervations between VCN-MNTB and their maturation. Accordingly, a complete block of neurotransmission, such as in the $\mathrm{KO}$ of Munc18, Munc13, or Choline acetyltransferase genes (Verhage et al., 2000; Misgeld et al., 2002; Varoqueaux et al., 2002), does not affect initial axonal targeting and synaptogenesis.

\section{Synergistic roles of synaptic activity and cellular signaling in synapse development}

How does dynamin 1- and 3-mediated endocytosis regulate $\mathrm{CH}$ development? Multiple mechanisms could synergistically contribute to this process. The most parsimonious explanation is that severe defects in synaptic endocytosis and transmission in cDKO diminish neural network activity in vivo and lead to impaired $\mathrm{CH}$ formation because the neural activity is crucial for synaptic development (Andreae and Burrone, 2014). In addition, chronic alterations in cellular signaling associated with broad endocytosis defects (Cosker and Segal, 2014), such as dysfunction of neurotrophic factor release, its receptor trafficking and endosomal signaling (Zweifel et al., 2005), may synergistically contribute to this process. Figure 10 shows a simplified model to explain the deficient synaptic development of $\mathrm{CH}$ in $\mathrm{cDKO}$ mice. The loss of dynamin 1 and 3 strongly impairs clathrin-mediated endocytosis and thus the sufficient vesicle recycling and neurotransmission that may be required for normal $\mathrm{CH}$ development. The persistent loss of synaptic activity, as well as alterations in intracellular signaling associated with a broad endocytosis defect (data not shown in the diagram), contributes to the severe impairment of $\mathrm{CH}$ formation, maturation, and subsequent survival.

Neural activity plays both instructive and trophic roles through $\mathrm{Ca}^{2+}$-dependent gene transcription (Flavell and Greenberg, 2008). Consistently, abrupt $\mathrm{CH}$ growth is closely matched with rapid increases in synaptic strength (Hoffpauir et al., 2006; Nakamura and Cramer, 2011; Yu and Goodrich, 2014). Our data showed that $\mathrm{CH}$ developmental defects in different combinations of dynamin cKOs closely parallel the extent of defects in vesicle endocytosis and synaptic activity, such as dim vGlut 1 fluorescence in cDKO MNTB. This is consistent with the $10 \times$ smaller ESPC amplitude (Raimondi et al., 2011) and nearly diminished spontaneous network activity in neuronal cultures (Lou et al., 2012).

Among 3 dynamin isoforms, dynamin 1 and 3 are enriched in synapses (Gray et al., 2003; Raimondi et al., 2011), indicating 
A

P4

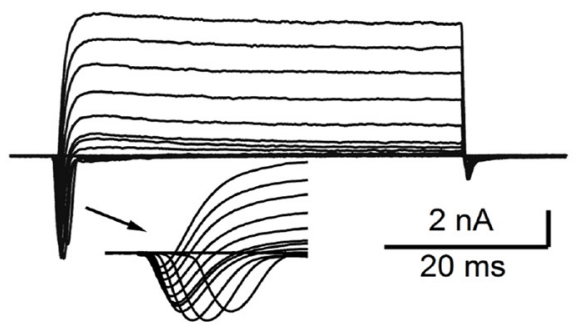

B

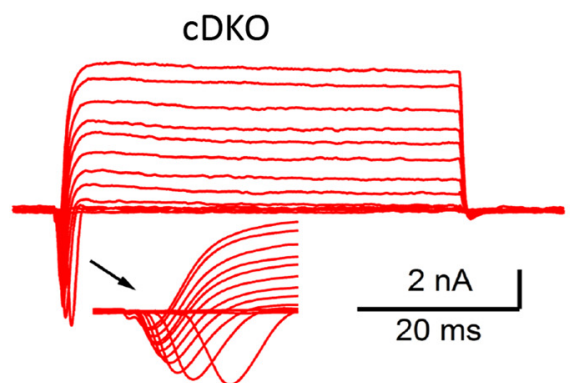

C $\mathrm{P3}-4$

Control

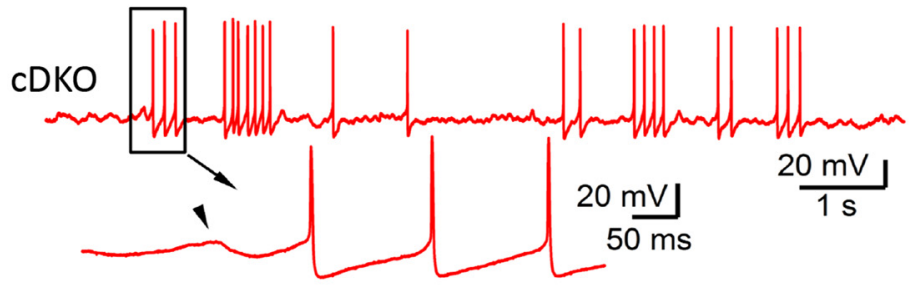

D $\quad$ P3-4 P5-6

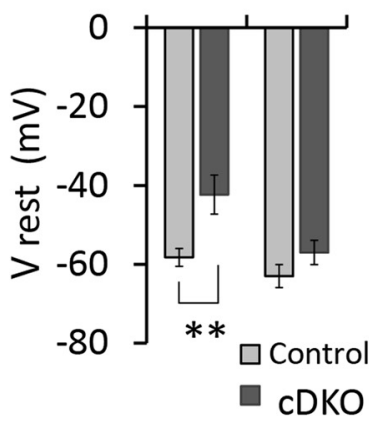

E
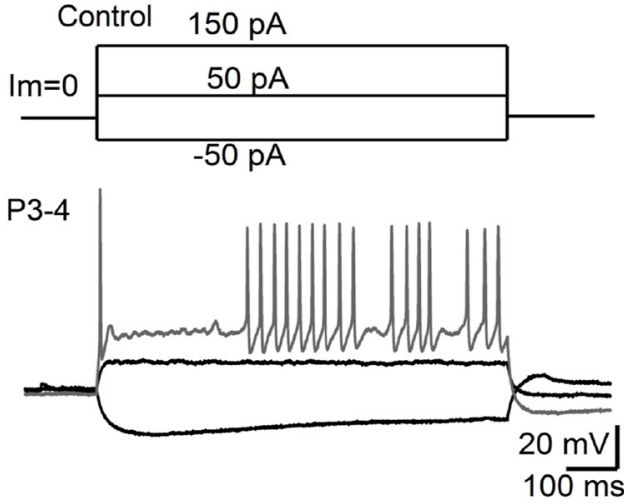

$\mathbf{F}$

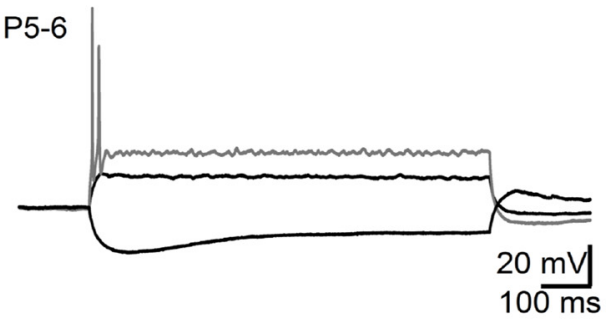

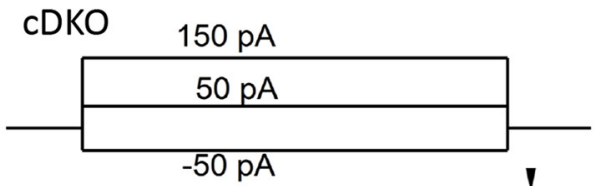
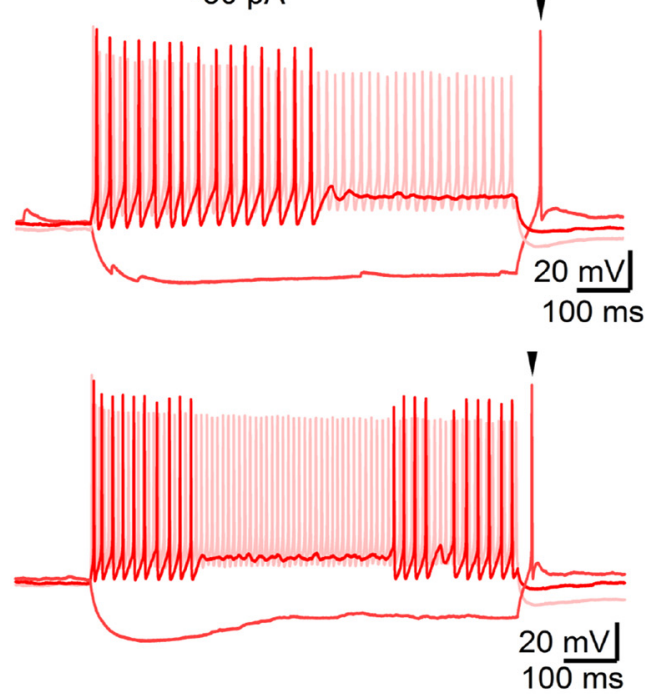

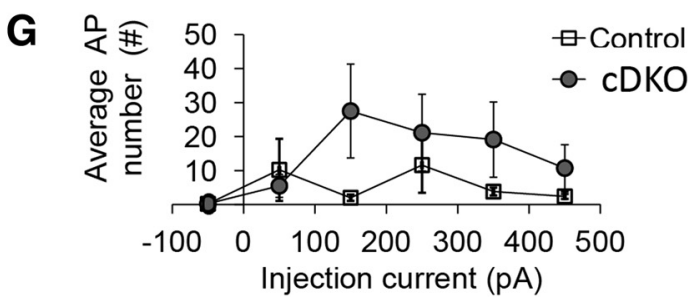

Figure 9. Increased membrane excitability of MNTB neurons in CDKO mice over controls. $A, B$, Representative whole-cell patch-clamp recordings from P4 MNTB neurons. Insets, Expanded views of inward currents. $C$, Spontaneous action potentials in CDKO (bottom) but not in control (top) neurons recorded under current clamp from MNTB neurons. $D$, Developmental decrease in resting membrane potentials was delayed in CDKO neurons ( $n=6$ and $n=5$ for control and $C D K 0$ at P3-P4, $p=0.0079 ; n=5$ and $n=8$ neurons at P9-P10, $p=0.38$ ). E, Different AP firing patterns in P3-P4 MNTB neurons (bottom) during current injections (top). Arrowhead indicates an AP triggered immediately after the end of negative current injection. $F$, Similar to $E$, but at P5-P6. Note the tonic APs in CDKO, but not in control neurons, at this age. G, AP numbers during current injections in CDKO $(n=5)$ and control $(n=8)$ neurons at P5-P6. ${ }^{* *} p<0.01$. 
their primary function at synapses over nonsynaptic regions. The demand of vesicle endocytosis is significantly higher in the presynaptic than the postsynaptic side due to vigorous vesicle recycling in the nerve terminals. Both dynamin 1 and 3 are present in postsynaptic sides (Fig. 1) and were removed in cDKO synapses. The postsynaptic endocytosis is known to affect spine morphogenesis (Gray et al., 2003, 2005) and AMPA receptor trafficking (Kennedy and Ehlers, 2006; Lu et al., 2007) and to release trophic factors that regulate synaptic development (e.g., BMP) (Bayat et al., 2011; Xiao et al., 2013). Thus, the postsynaptic endocytosis defect may affect these processes and partially contribute the impaired $\mathrm{CH}$ development in cDKO. Indeed, we observed slower sEPSC kinetics in CDKO, suggesting a deficit in postsynaptic maturation toward the switch of AMPA receptor subunits.

Dynamin 1 and 3 levels rapidly increase during development (Fig. 1), which parallels the fast $\mathrm{CH}$ formation and synaptic activity increase. Abundant dynamin may be critical for high capacity of vigorous synaptic vesicle regeneration because $\mathrm{CH}$ is a tonic synapse in vivo that constantly fires spontaneous high-frequency APs (71 Hz on average) (Lorteije et al., 2009) and could follow $>600$ $\mathrm{Hz}$ AP stimulation (Hermann et al., 2007). Our data agree well with dynamin upregulation during development (Nakata et al., 1991; Cnops et al., 2007; Ferguson et al., 2007; Boumil et al., 2010) and the endocytosis rate/capacity increase during $\mathrm{CH}$ maturation (Renden and von Gersdorff, 2007).

Dynamin 1 and 3 cDKO nearly abolished $\mathrm{CH}$ formation in MNTBs (Fig. 5). This phenotype is much more severe than interruptions of auditory sensory input activity, such as cochlear ablation, sound deprivation (Grande et al., 2014), congenital deafness (Leao et al., 2006; Youssoufian et al., 2008), and otoferlin (Wright et al., 2014) or $\mathrm{Ca}_{\mathrm{V}} 1.3$ (ErazoFischer et al., 2007; Hirtz et al., 2011, 2012). The remaining spontaneous neural activity and miniature release in the brainstem in vivo might explain the moderate defects at $\mathrm{CH}$, similar to the case of $\mathrm{CH}$ development before hearing onset (Sonntag et al., 2009; Tritsch et al., 2010; Crins et al., 2011; Rusu and Borst, 2011). It was shown that $\mathrm{CH}$ could fire spontaneous APs at a median frequency of 35 spikes/s on P11-P12 (Sonntag et al., 2009). In addition, miniature neurotransmission has been shown to be sufficient for synapse development at NMJ (Choi et al., 2014).

In addition to neural activity, the loss of dynamin 1 and 3 might cause alterations in cellular signaling and neural development due to both synaptic and nonsynaptic endocytosis defects. Dynamin-mediated endocytosis might regulate surface receptor trafficking and endosomal signaling (Bökel and Brand, 2014; Cosker and Segal, 2014), as well as cell cytoskeleton dynamic (Orth and McNiven, 2003; Itoh et al., 2005; Ferguson et al., 2009; Fan et al., 2015). Chronic accumulation of these defects, synap-

\section{B Dynamin 1 and 3 cDKO}

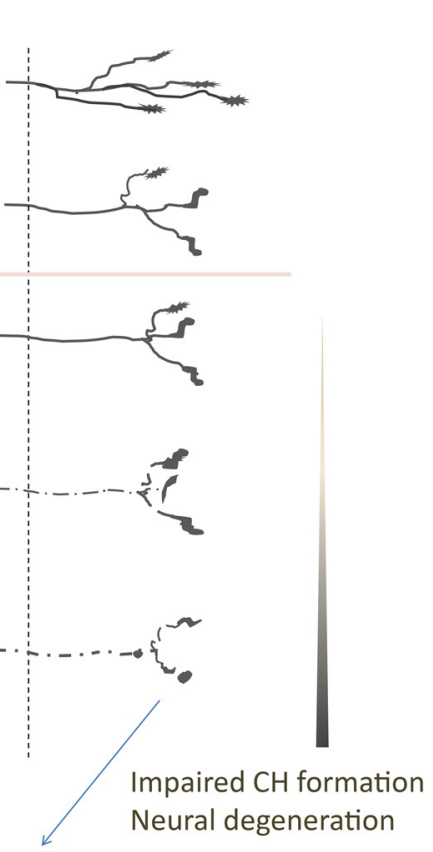

\section{$\mathrm{CH}$ formation} and maturation Neural degeneration

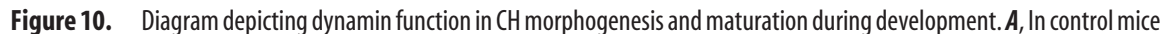
the growth cones from $\mathrm{GBC}$ axons cross the midline and make numerous small synaptic connections by $\mathrm{P} 2$; these small synapse

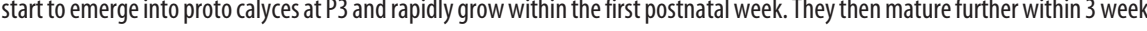
during abrupt $\mathrm{CH}$ formation and rapid neural development. At a later developmental stage, CHs and MNTB neurons gradually degenerate, accompanied by persistent endocytic defect and insufficient synaptic activity, as well as abnormal cellular signaling Vesicle

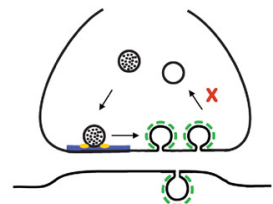
associated with endocytosis defect. Inset, Endocytic defects at synapses in the absence of dynamin 1 and 3.

tically and neuron-wide, might influence neural development. This effect might partially contribute to the smaller MNTBs, decreased axon bundle, and progressive neural degeneration in this study. Genetic studies in Drosophila have identified multiple signaling pathways that are important for NMJ development, such as WNT, mitogen-activated protein kinase, and BMP/transforming growth factor $\beta$ (Bayat et al., 2011). It was reported that $\mathrm{KO}$ of $\mathrm{BMP}$ receptors $\mathrm{la} / \mathrm{b}$ in mice leads to smaller $\mathrm{CH}$ size and multiple innervations in MNTBs (Xiao et al., 2013). In addition, BMP signaling also participates in embryo hindbrain patterning (Graham et al., 1996; Tümpel et al., 2009). Future work is required to explore how endocytosis might regulate these signaling pathways to influence synaptic development.

Genetic studies highlight a more important role of dynamin 2 than dynamin 1 and 3 in early neural development. Dynamin 2 is embryonic lethal (Ferguson et al., 2009); its cKO in earlier neuronal progenitors, but not its postnatal deletion, impairs brain development (Ferguson and De Camilli, 2012). Dynamin 1 and 3 express levels that are low at P1 and rapidly boost up (Fig. 1) when synaptic transmission and network activity increase, consistent 
with its primary function in synaptic endocytosis and neurotransmission. However, their potential role in early neural development cannot be ruled out because the Krox20Cre expression in the brainstem starts at E9. Dynamin 1 and 3 might influence neuronal proliferation, migration, and earlier morphogenesis as dynamin 2 does albeit less critical; these effects later might indirectly affect the $\mathrm{CH}$ development observed in the cDKO.

\section{References}

Andreae LC, Burrone J (2014) The role of neuronal activity and transmitter release on synapse formation. Curr Opin Neurobiol 27:47-52. CrossRef Medline

Atwood HL, Karunanithi S (2002) Diversification of synaptic strength: presynaptic elements. Nat Rev Neurosci 3:497-516. CrossRef Medline

Barres BA (2008) The mystery and magic of glia: a perspective on their roles in health and disease. Neuron 60:430-440. CrossRef Medline

Bayat V, Jaiswal M, Bellen HJ (2011) The BMP signaling pathway at the Drosophila neuromuscular junction and its links to neurodegenerative diseases. Curr Opin Neurobiol 21:182-188. CrossRef Medline

Bökel C, Brand M (2014) Endocytosis and signaling during development. Cold Spring Harb Perspect Biol 6:a017020. CrossRef Medline

Borst JG, Soria van Hoeve J (2012) The calyx of Held synapse: from model synapse to auditory relay. Annu Rev Physiol 74:199-224. Medline

Boumil RM, Letts VA, Roberts MC, Lenz C, Mahaffey CL, Zhang ZW, Moser T, Frankel WN (2010) A missense mutation in a highly conserved alternate exon of dynamin-1 causes epilepsy in fitful mice. PLoS Genet 6:e1001046. CrossRef Medline

Cao H, Garcia F, McNiven MA (1998) Differential distribution of dynamin isoforms in mammalian cells. Mol Biol Cell 9:2595-2609. CrossRef Medline

Chatonnet F, Wrobel LJ, Mézières V, Pasqualetti M, Ducret S, Taillebourg E, Charnay P, Rijli FM, Champagnat J (2007) Distinct roles of Hoxa2 and Krox20 in the development of rhythmic neural networks controlling inspiratory depth, respiratory frequency, and jaw opening. Neural Dev 2:19. CrossRef Medline

Choi BJ, Imlach WL, Jiao W, Wolfram V, Wu Y, Grbic M, Cela C, Baines RA, Nitabach MN, McCabe BD (2014) Miniature neurotransmission regulates Drosophila synaptic structural maturation. Neuron 82:618-634. CrossRef Medline

Clements JD, Bekkers JM (1997) Detection of spontaneous synaptic events with an optimally scaled template. Biophys J 73:220-229. CrossRef Medline

Cnops L, Hu TT, Vanden Broeck J, Burnat K, Van Den Bergh G, Arckens L (2007) Age- and experience-dependent expression of dynamin I and synaptotagmin I in cat visual system. J Comp Neurol 504:254-264. CrossRef Medline

Cosker KE, Segal RA (2014) Neuronal signaling through endocytosis. Cold Spring Harb Perspect Biol 6:a020669. CrossRef Medline

Cremona O, Di Paolo G, Wenk MR, Lüthi A, Kim WT, Takei K, Daniell L, Nemoto Y, Shears SB, Flavell RA, McCormick DA, De Camilli P (1999) Essential role of phosphoinositide metabolism in synaptic vesicle recycling. Cell 99:179-188. CrossRef Medline

Crins TT, Rusu SI, Rodríguez-Contreras A, Borst JG (2011) Developmental changes in short-term plasticity at the rat calyx of Held synapse. J Neurosci 31:11706-11717. CrossRef Medline

Dickman DK, Lu Z, Meinertzhagen IA, Schwarz TL (2006) Altered synaptic development and active zone spacing in endocytosis mutants. Curr Biol 16:591-598. CrossRef Medline

Erazo-Fischer E, Striessnig J, Taschenberger H (2007) The role of physiological afferent nerve activity during in vivo maturation of the calyx of Held synapse. J Neurosci 27:1725-1737. CrossRef Medline

Fan F, Ji C, Wu Y, Ferguson SM, Tamarina N, Philipson LH, Lou X (2015) Dynamin 2 regulates biphasic insulin secretion and plasma glucose homeostasis. J Clin Invest 125:4026-4041. CrossRef Medline

Fedchyshyn MJ, Wang LY (2005) Developmental transformation of the release modality at the calyx of Held synapse. J Neurosci 25:4131-4140. CrossRef Medline

Felmy F, Schneggenburger R (2004) Developmental expression of the $\mathrm{Ca}^{2+}$-binding proteins calretinin and parvalbumin at the calyx of Held of rats and mice. Eur J Neurosci 20:1473-1482. CrossRef Medline
Ferguson SM, De Camilli P (2012) Dynamin, a membrane-remodelling GTPase. Nat Rev Mol Cell Biol 13:75-88. CrossRef Medline

Ferguson SM, Brasnjo G, Hayashi M, Wölfel M, Collesi C, Giovedi S, Raimondi A, Gong LW, Ariel P, Paradise S, O’Toole E, Flavell R, Cremona O, Miesenböck G, Ryan TA, De Camilli P (2007) A selective activitydependent requirement for dynamin 1 in synaptic vesicle endocytosis. Science 316:570-574. CrossRef Medline

Ferguson SM, Raimondi A, Paradise S, Shen H, Mesaki K, Ferguson A, Destaing O, Ko G, Takasaki J, Cremona O, O’Toole E, De Camilli P (2009) Coordinated actions of actin and BAR proteins upstream of dynamin at endocytic clathrin-coated pits. Dev Cell 17:811-822. CrossRef Medline

Flavell SW, Greenberg ME (2008) Signaling mechanisms linking neuronal activity to gene expression and plasticity of the nervous system. Annu Rev Neurosci 31:563-590. CrossRef Medline

Graham A, Koentges G, Lumsden A (1996) Neural crest apoptosis and the establishment of craniofacial pattern: an honorable death. Mol Cell Neurosci 8:76-83. CrossRef Medline

Grande G, Negandhi J, Harrison RV, Wang LY (2014) Remodelling at the calyx of Held-MNTB synapse in mice developing with unilateral conductive hearing loss. J Physiol 592:1581-1600. CrossRef Medline

Gray NW, Fourgeaud L, Huang B, Chen J, Cao H, Oswald BJ, Hémar A, McNiven MA (2003) Dynamin 3 is a component of the postsynapse, where it interacts with mGluR5 and Homer. Curr Biol 13:510-515. CrossRef Medline

Gray NW, Kruchten AE, Chen J, McNiven MA (2005) A dynamin-3 spliced variant modulates the actin/cortactin-dependent morphogenesis of dendritic spines. J Cell Sci 118:1279-1290. CrossRef Medline

Hamann M, Billups B, Forsythe ID (2003) Non-calyceal excitatory inputs mediate low fidelity synaptic transmission in rat auditory brainstem slices. Eur J Neurosci 18:2899-2902. CrossRef Medline

Han Y, Kaeser PS, Südhof TC, Schneggenburger R (2011) RIM determines $\mathrm{Ca}(2)+$ channel density and vesicle docking at the presynaptic active zone. Neuron 69:304-316. CrossRef Medline

Hermann J, Pecka M, von Gersdorff H, Grothe B, Klug A (2007) Synaptic transmission at the calyx of Held under in vivo like activity levels. J Neurophysiol 98:807-820. CrossRef Medline

Hiesinger PR, Zhai RG, Zhou Y, Koh TW, Mehta SQ, Schulze KL, Cao Y, Verstreken P, Clandinin TR, Fischbach KF, Meinertzhagen IA, Bellen HJ (2006) Activity-independent prespecification of synaptic partners in the visual map of Drosophila. Curr Biol 16:1835-1843. CrossRef Medline

Hirtz JJ, Boesen M, Braun N, Deitmer JW, Kramer F, Lohr C, Müller B, Nothwang HG, Striessnig J, Löhrke S, Friauf E (2011) Cavl.3 calcium channels are required for normal development of the auditory brainstem. J Neurosci 31:8280-8294. CrossRef Medline

Hirtz JJ, Braun N, Griesemer D, Hannes C, Janz K, Löhrke S, Müller B, Friauf E (2012) Synaptic refinement of an inhibitory topographic map in the auditory brainstem requires functional Cav1.3 calcium channels. J Neurosci 32:14602-14616. CrossRef Medline

Hoffpauir BK, Grimes JL, Mathers PH, Spirou GA (2006) Synaptogenesis of the calyx of Held: rapid onset of function and one-to-one morphological innervation. J Neurosci 26:5511-5523. CrossRef Medline

Hoffpauir BK, Kolson DR, Mathers PH, Spirou GA (2010) Maturation of synaptic partners: functional phenotype and synaptic organization tuned in synchrony. J Physiol 588:4365-4385. CrossRef Medline

Holcomb PS, Hoffpauir BK, Hoyson MC, Jackson DR, Deerinck TJ, Marrs GS, Dehoff M, Wu J, Ellisman MH, Spirou GA (2013) Synaptic inputs compete during rapid formation of the calyx of Held: a new model system for neural development. J Neurosci 33:12954-12969. CrossRef Medline

Howell DM, Morgan WJ, Jarjour AA, Spirou GA, Berrebi AS, Kennedy TE, Mathers PH (2007) Molecular guidance cues necessary for axon pathfinding from the ventral cochlear nucleus. J Comp Neurol 504:533-549. CrossRef Medline

Hsieh CY, Nakamura PA, Luk SO, Miko IJ, Henkemeyer M, Cramer KS (2010) Ephrin-B reverse signaling is required for formation of strictly contralateral auditory brainstem pathways. J Neurosci 30:9840-9849. CrossRef Medline

Itoh T, Erdmann KS, Roux A, Habermann B, Werner H, De Camilli P (2005) Dynamin and the actin cytoskeleton cooperatively regulate plasma membrane invagination by BAR and F-BAR proteins. Dev Cell 9:791-804. CrossRef Medline

Joshi I, Shokralla S, Titis P, Wang LY (2004) The role of AMPA receptor 
gating in the development of high-fidelity neurotransmission at the calyx of Held synapse. J Neurosci 24:183-196. CrossRef Medline

Kennedy MJ, Ehlers MD (2006) Organelles and trafficking machinery for postsynaptic plasticity. Annu Rev Neurosci 29:325-362. CrossRef Medline

Kettenmann H, Hanisch UK, Noda M, Verkhratsky A (2011) Physiology of microglia. Physiol Rev 91:461-553. CrossRef Medline

Kochubey O, Lou X, Schneggenburger R (2011) Regulation of transmitter release by $\mathrm{Ca}(2+)$ and synaptotagmin: insights from a large CNS synapse. Trends Neurosci 34:237-246. CrossRef Medline

Koh TW, Verstreken P, Bellen HJ (2004) Dap160/intersectin acts as a stabilizing scaffold required for synaptic development and vesicle endocytosis. Neuron 43:193-205. CrossRef Medline

Koike-Tani M, Saitoh N, Takahashi T (2005) Mechanisms underlying developmental speeding in AMPA-EPSC decay time at the calyx of Held. J Neurosci 25:199-207. CrossRef Medline

Kononenko NL, Puchkov D, Classen GA, Walter AM, Pechstein A, Sawade L, Kaempf N, Trimbuch T, Lorenz D, Rosenmund C, Maritzen T, Haucke V (2014) Clathrin/AP-2 mediate synaptic vesicle reformation from endosome-like vacuoles but are not essential for membrane retrieval at central synapses. Neuron 82:981-988. CrossRef Medline

Leao RN, Sun H, Svahn K, Berntson A, Youssoufian M, Paolini AG, Fyffe RE, Walmsley B (2006) Topographic organization in the auditory brainstem of juvenile mice is disrupted in congenital deafness. J Physiol 571: 563-578. CrossRef Medline

Liu YW, Neumann S, Ramachandran R, Ferguson SM, Pucadyil TJ, Schmid SL (2011) Differential curvature sensing and generating activities of dynamin isoforms provide opportunities for tissue-specific regulation. Proc Natl Acad Sci U S A 108:E234-E242. CrossRef Medline

Lorteije JA, Rusu SI, Kushmerick C, Borst JG (2009) Reliability and precision of the mouse calyx of Held synapse. J Neurosci 29:13770-13784. CrossRef Medline

Lou X, Korogod N, Brose N, Schneggenburger R (2008a) Phorbol esters modulate spontaneous and $\mathrm{Ca}^{2+}$-evoked transmitter release via acting on both Munc13 and protein kinase C. J Neurosci 28:8257-8267. CrossRef Medline

Lou X, Paradise S, Ferguson SM, De Camilli P (2008b) Selective saturation of slow endocytosis at a giant glutamatergic central synapse lacking dynamin 1. Proc Natl Acad Sci U S A 105:17555-17560. CrossRef Medline

Lou X, Fan F, Messa M, Raimondi A, Wu Y, Looger LL, Ferguson SM, De Camilli P (2012) Reduced release probability prevents vesicle depletion and transmission failure at dynamin mutant synapses. Proc Natl Acad Sci U S A 109:E515-E523. CrossRef Medline

Lu J, Helton TD, Blanpied TA, Rácz B, Newpher TM, Weinberg RJ, Ehlers MD (2007) Postsynaptic positioning of endocytic zones and AMPA receptor cycling by physical coupling of dynamin-3 to Homer. Neuron 55:874-889. CrossRef Medline

Mahapatra S, Fan F, Lou X (2016) Tissue-specific dynamin-1 deletion at the calyx of Held decreases short-term synaptic depression through a mechanism distinct from vesicle resupply Proc Natl Acad Sci U S A. Advance online publication. Retrieved. doi: 10.1073/pnas.1520937113.

Marie B, Sweeney ST, Poskanzer KE, Roos J, Kelly RB, Davis GW (2004) Dap160/intersectin scaffolds the periactive zone to achieve high-fidelity endocytosis and normal synaptic growth. Neuron 43:207-219. CrossRef Medline

McAllister AK (2007) Dynamic aspects of CNS synapse formation. Annu Rev Neurosci 30:425-450. CrossRef Medline

Melom JE, Littleton JT (2011) Synapse development in health and disease. Curr Opin Genet Dev 21:256-261. CrossRef Medline

Michalski N, Babai N, Renier N, Perkel DJ, Chédotal A, Schneggenburger R (2013) Robo3-driven axon midline crossing conditions functional maturation of a large commissural synapse. Neuron 78:855-868. CrossRef Medline

Milosevic I, Giovedi S, Lou X, Raimondi A, Collesi C, Shen H, Paradise S, O’Toole E, Ferguson S, Cremona O, De Camilli P (2011) Recruitment of endophilin to clathrin-coated pit necks is required for efficient vesicle uncoating after fission. Neuron 72:587-601. CrossRef Medline

Misgeld T, Burgess RW, Lewis RM, Cunningham JM, Lichtman JW, Sanes JR (2002) Roles of neurotransmitter in synapse formation: development of neuromuscular junctions lacking choline acetyltransferase. Neuron 36: 635-648. CrossRef Medline
Muzumdar MD, Tasic B, Miyamichi K, Li L, Luo L (2007) A global doublefluorescent Cre reporter mouse. Genesis 45:593-605. CrossRef Medline

Nakamura PA, Cramer KS (2011) Formation and maturation of the calyx of Held. Hear Res 276:70-78. CrossRef Medline

Nakata T, Iwamoto A, Noda Y, Takemura R, Yoshikura H, Hirokawa N (1991) Predominant and developmentally regulated expression of dynamin in neurons. Neuron 7:461-469. CrossRef Medline

Neher E, Sakaba T (2008) Multiple roles of calcium ions in the regulation of neurotransmitter release. Neuron 59:861-872. CrossRef Medline

O'Connor-Giles KM, Ho LL, Ganetzky B (2008) Nervous wreck interacts with thickveins and the endocytic machinery to attenuate retrograde BMP signaling during synaptic growth. Neuron 58:507-518. CrossRef Medline

Orth JD, McNiven MA (2003) Dynamin at the actin-membrane interface. Curr Opin Cell Biol 15:31-39. CrossRef Medline

Park RJ, Shen H, Liu L, Liu X, Ferguson SM, De Camilli P (2013) Dynamin triple knockout cells reveal off target effects of commonly used dynamin inhibitors. J Cell Sci 126:5305-5312. CrossRef Medline

Petrof I, Sherman SM (2013) Functional significance of synaptic terminal size in glutamatergic sensory pathways in thalamus and cortex. J Physiol 591:3125-3131. CrossRef Medline

Qiu X, Zhu Q, Sun J (2015) Quantitative analysis of vesicle recycling at the calyx of Held synapse. Proc Natl Acad Sci U S A 112:4779-4784. CrossRef Medline

Raimondi A, Ferguson SM, Lou X, Armbruster M, Paradise S, Giovedi S, Messa M, Kono N, Takasaki J, Cappello V, O’Toole E, Ryan TA, De Camilli P (2011) Overlapping role of dynamin isoforms in synaptic vesicle endocytosis. Neuron 70:1100-1114. CrossRef Medline

Renden R, von Gersdorff H (2007) Synaptic vesicle endocytosis at a CNS nerve terminal: faster kinetics at physiological temperatures and increased endocytotic capacity during maturation. J Neurophysiol 98:3349-3359. CrossRef Medline

Rodríguez-Contreras A, van Hoeve JS, Habets RL, Locher H, Borst JG (2008) Dynamic development of the calyx of Held synapse. Proc Natl Acad Sci U S A 105:5603-5608. CrossRef Medline

Rusu SI, Borst JG (2011) Developmental changes in intrinsic excitability of principal neurons in the rat medial nucleus of the trapezoid body. Dev Neurobiol 71:284-295. CrossRef Medline

Saheki Y, De Camilli P (2012) Synaptic vesicle endocytosis. Cold Spring Harb Perspect Biol 4:a005645. CrossRef Medline

Sanes JR, Yamagata M (2009) Many paths to synaptic specificity. Annu Rev Cell Dev Biol 25:161-195. CrossRef Medline

Sätzler K, Sohl LF, Bollmann JH, Borst JG, Frotscher M, Sakmann B, Lubke JH (2002) Three-dimensional reconstruction of a calyx of Held and its postsynaptic principal neuron in the medial nucleus of the trapezoid body. J Neurosci 22:10567-10579. Medline

Schneggenburger R, Forsythe ID (2006) The calyx of Held. Cell Tissue Res 326:311-337. CrossRef Medline

Sonntag M, Englitz B, Kopp-Scheinpflug C, Rübsamen R (2009) Early postnatal development of spontaneous and acoustically evoked discharge activity of principal cells of the medial nucleus of the trapezoid body: an in vivo study in mice. J Neurosci 29:9510-9520. CrossRef Medline

Soria Van Hoeve JS, Borst JG (2010) Delayed appearance of the scaffolding proteins PSD-95 and Homer-1 at the developing rat calyx of Held synapse. J Comp Neurol 518:4581-4590. CrossRef Medline

Takahashi T (2005) Postsynaptic receptor mechanisms underlying developmental speeding of synaptic transmission. Neurosci Res 53:229-240. CrossRef Medline

Taschenberger H, von Gersdorff H (2000) Fine-tuning an auditory synapse for speed and fidelity: developmental changes in presynaptic waveform, EPSC kinetics, and synaptic plasticity. J Neurosci 20:9162-9173. Medline

Taschenberger H, Leão RM, Rowland KC, Spirou GA, von Gersdorff H (2002) Optimizing synaptic architecture and efficiency for highfrequency transmission. Neuron 36:1127-1143. CrossRef Medline

Tritsch NX, Rodríguez-Contreras A, Crins TT, Wang HC, Borst JG, Bergles DE (2010) Calcium action potentials in hair cells pattern auditory neuron activity before hearing onset. Nat Neurosci 13:1050-1052. CrossRef Medline

Tümpel S, Wiedemann LM, Krumlauf R (2009) Hox genes and segmentation of the vertebrate hindbrain. Curr Top Dev Biol 88:103-137. CrossRef Medline

Varoqueaux F, Sigler A, Rhee JS, Brose N, Enk C, Reim K, Rosenmund C (2002) Total arrest of spontaneous and evoked synaptic transmission but 
normal synaptogenesis in the absence of Munc13-mediated vesicle priming. Proc Natl Acad Sci U S A 99:9037-9042. CrossRef Medline

Verhage M, Maia AS, Plomp JJ, Brussaard AB, Heeroma JH, Vermeer H, Toonen RF, Hammer RE, van den Berg TK, Missler M, Geuze HJ, Südhof TC (2000) Synaptic assembly of the brain in the absence of neurotransmitter secretion. Science 287:864-869. CrossRef Medline

Voiculescu O, Charnay P, Schneider-Maunoury S (2000) Expression pattern of a Krox-20/Cre knock-in allele in the developing hindbrain, bones, and peripheral nervous system. Genesis 26:123-126. CrossRef Medline

von Gersdorff H, Borst JG (2002) Short-term plasticity at the calyx of Held. Nat Rev Neurosci 3:53-64. CrossRef Medline

Walmsley B, Alvarez FJ, Fyffe RE (1998) Diversity of structure and function at mammalian central synapses. Trends Neurosci 21:81-88. CrossRef Medline

Wimmer VC, Horstmann H, Groh A, Kuner T (2006) Donut-like topology of synaptic vesicles with a central cluster of mitochondria wrapped into membrane protrusions: a novel structure-function module of the adult calyx of Held. J Neurosci 26:109-116. CrossRef Medline

Wright S, Hwang Y, Oertel D (2014) Synaptic transmission between end bulbs of Held and bushy cells in the cochlear nucleus of mice with a mutation in Otoferlin. J Neurophysiol 112:3173-3188. CrossRef Medline

Wu LG, Hamid E, Shin W, Chiang HC (2014a) Exocytosis and endocytosis: modes, functions, and coupling mechanisms. Annu Rev Physiol 76: 301-331. CrossRef Medline
Wu Y, O’Toole ET, Girard M, Ritter B, Messa M, Liu X, McPherson PS, Ferguson SM, De Camilli P (2014b) A dynamin 1-, dynamin 3- and clathrin-independent pathway of synaptic vesicle recycling mediated by bulk endocytosis. Elife 3:e01621. CrossRef Medline

Xiao L, Michalski N, Kronander E, Gjoni E, Genoud C, Knott G, Schneggenburger R (2013) BMP signaling specifies the development of a large and fast CNS synapse. Nat Neurosci 16:856-864. CrossRef Medline

Yang YM, Fedchyshyn MJ, Grande G, Aitoubah J, Tsang CW, Xie H, Ackerley CA, Trimble WS, Wang LY (2010) Septins regulate developmental switching from microdomain to nanodomain coupling of $\mathrm{Ca}(2+)$ influx to neurotransmitter release at a central synapse. Neuron 67:100-115. CrossRef Medline

Youssoufian M, Couchman K, Shivdasani MN, Paolini AG, Walmsley B (2008) Maturation of auditory brainstem projections and calyces in the congenitally deaf (dn/dn) mouse. J Comp Neurol 506:442-451. CrossRef Medline

Yu WM, Goodrich LV (2014) Morphological and physiological development of auditory synapses. Hear Res 311:3-16. CrossRef Medline

Zhao L, Wang D, Wang Q, Rodal AA, Zhang YQ (2013) Drosophila cyfip regulates synaptic development and endocytosis by suppressing filamentous actin assembly. PLoS Genet 9:e1003450. CrossRef Medline

Zweifel LS, Kuruvilla R, Ginty DD (2005) Functions and mechanisms of retrograde neurotrophin signalling. Nat Rev Neurosci 6:615-625. CrossRef Medline 